\title{
The Interactive Antimicrobial Activity of Conventional Antibiotics and Petalostigma spp. Extracts Against Bacterial Triggers of some Autoimmune Inflammatory Diseases
}

\author{
Aishwarya Ilanko', Ian Edwin Cock ${ }^{1,2, *}$
}

Aishwarya llanko', Ian Edwin Cock ${ }^{1,2, *}$

'School of Natural Sciences, Nathan Campus, Griffith University, Brisbane, AUSTRALIA.

${ }^{2}$ Environmental Futures Research Institute, Nathan Campus, Griffith University, Brisbane, AUSTRALIA.

\section{Correspondence}

Dr. Ian Edwin Cock

Environmental Futures Research Institute, Nathan Campus, Griffith University, Brisbane, AUSTRALIA.

Phone no : +61737357637

E-mail: I.Cock@griffith.edu.au

History

- Submission Date: 07-10-2018;

- Review completed: 12-11-2018;

- Accepted Date: 28-11-2018.

DOI : 10.5530/pj.2019.11.45

\section{Article Available online}

http://www.phcogj.com/v11/i2

\section{Copyright}

(C) 2019 Phcog.Net. This is an openaccess article distributed under the terms of the Creative Commons Attribution 4.0 International license.

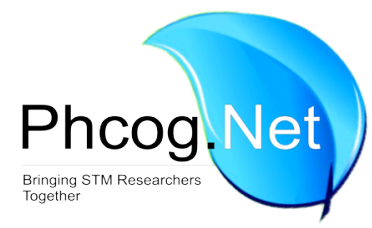

\begin{abstract}
Introduction: An increase in antibiotic resistance and a corresponding decrease in antimicrobial discovery have directed researchers towards alternative therapies, including plant-based medicines. However, synergistic combinations of plant extracts with conventional antibiotics are a far more effective approach in overcoming resistance and potentiating the activity of antibiotics that are otherwise ineffective against resistant bacterial strains. Methods: In this study, Petalostigma spp. (native Australian medicinal plants) extracts were combined with a range of conventional antibiotics and tested against various microbial triggers of autoimmune diseases. The fruit and leaves were extracted separately with solvents of varying polarity and investigated for the ability to inhibit bacterial growth using disc diffusion and liquid dilution MIC techniques. Results: The methanolic and water extracts showed low to moderate inhibitory activity against several microbes. However, combinations of the mid-low polarity extracts with conventional antibiotics proved significantly more effective in inhibiting the growth of Proteus mirabilis and Acinetobacter baylyi (bacterial triggers of rheumatoid arthritis and multiple sclerosis respectively). In total, 14 different combinations proved to be synergistic. Notably, two antibiotics (chloramphenicol and erythromycin) with no inhibitory activity against $P$. mirabilis alone were shown to have substantial activity when tested in combination with Petalostigma spp. extracts. Conclusion: Although the mechanisms of synergy are still unclear, studies indicate that compounds within Petalostigma spp. may mimic the actions of resistance modifying agents, thus potentiating the activity of several antibiotics that are relatively ineffective alone. Isolation of these agents may be highly beneficial in drug design against several bacteria including the microbial triggers of rheumatoid arthritis and multiple sclerosis. Key words: Synergy, Conventional antimicrobials, Interaction, Medicinal plants, Rheumatoid arthritis, Ankylosing spondylitis, Multiple sclerosis, Drug combinations, Efflux pump inhibitor.
\end{abstract}

\section{INTRODUCTION}

Autoimmune inflammatory disorders including ankylosing spondylitis, multiple sclerosis, rheumatoid arthritis and rheumatic fever are a group of debilitating conditions that afflict genetically susceptible individuals. They are triggered by exposure to specific exogenous antigens, with bacterial antigens being the most important. Whilst the triggers of some autoimmune diseases are still unknown, serotyping studies have identified the bacterial triggers of several of these conditions and the bacterial antigens responsible for the inducing an immune response. P. mirabilis, a normal part of the human gastrointestinal flora, has been identified as trigger of rheumatoid arthritis. ${ }^{1}$ Similarly, K. pneumoniae can initiate ankylosing spondylitis in genetically susceptible people and both A. baylyi and P. aeruginosa can initiate the onset of multiple sclerosis. ${ }^{1}$ The development of medicines targeting these specific bacterial triggers may prevent the disease onset. This would reduce the severity of the symptoms once the

disease has progressed, as well as blocking tissue damage.

Antibiotic therapeutics that inhibit the growth of these bacteria already exist and their use for prophylactic treatment may be an attractive option. However, the improper and misuse of antibiotics has resulted in antibiotic resistance. ${ }^{2}$ As a consequence, two main events have occurred in parallel throughout the last century. The discovery of antimicrobial agents has steadily decreased to no more than a few antibiotics synthesised or discovered in the last decade. ${ }^{3}$ Simultaneously, antibiotic resistance has risen to an all-time high, creating multi-resistant organisms that are becoming increasingly difficult to manage using the current range of available antibiotic chemotherapies. ${ }^{4}$ The development of alternative treatment methods is crucial and considered by the World Health Organisation (WHO) to

Cite this article: Ilanko A, Cock IE. The Interactive Antimicrobial Activity of Conventional Antibiotics and Petalostigma spp. Extracts Against Bacterial Triggers of some Autoimmune Inflammatory Diseases. Pharmacog J. 2019;11 (2):292-309. 
be perhaps the biggest challenge facing medical science. ${ }^{5}$ For a number of reasons reviewed elsewhere ${ }^{6}$ it is unlikely that the current methods of antibiotic discovery/development will be as successful in the future.

Traditional medicines have great potential for antimicrobial drug development. Despite this, relatively few plant derived antibiotic compounds are in common use. This is likely because synergistic interactions are often required to potentiate the antibacterial activity and purified compounds often have much lower activity than the crude extract. ${ }^{7}$ A combinational approach that allows synergistic interaction between plant extracts (or pure plant compounds) and conventional antibiotics may be more effective in combatting bacterial pathogens, especially antibiotic resistant strains. ${ }^{3,89}$ Combinational therapy is already preferred over mono-therapy in multiple life-threatening infectious diseases such as malaria, tuberculosis and HIV/AIDS due to its ability to target multiple facets of a disease and to curb resistance. ${ }^{5}$ A combination of plant extracts/isolated compounds with conventional antibiotics may also prove to have an economic advantage. ${ }^{7}$ Developing a new drug requires years of extensive and costly testing. However, combinational therapy can potentially restore an existing drug to a state of significantly reduced resistance, thereby bypassing the strenuous and expensive process of discovering new antimicrobial agents. ${ }^{7}$ Further advantages of synergistic interactions include increased efficiency, reduced side effects, increased stability and bioavailability and the need for lower doses in comparison to synthetic alternatives.?

Petalostigma pubescens Domin and Petalostigma triloculare Mull. Arg. are endemic Australian plants that were used traditionally as antimicrobial and antiseptic agents by indigenous Australians. ${ }^{10}$ Recent studies have demonstrated good antibacterial activity for both species against a panel of human pathogens. ${ }^{11}$ However, these plants are yet to be tested against the bacterial triggers of rheumatoid arthritis (Proteus mirabilis), ankylosing spondylitis (Klebsiella pneumoniae), multiple sclerosis (Acinetobacter baylyi, Pseudomonas aeruginosa) and rheumatic fever (Streptococcus pyogenes). ${ }^{12}$ Furthermore, Petalostigma spp. extracts are yet to be tested for bacterial growth inhibitory activity in combinational studies with conventional antibiotics. Therefore, this study investigates the antimicrobial effects of $P$. pubescens and $P$. triloculare and their ability to potentiate the growth inhibitory properties of conventional antibiotics against the bacterial triggers of some autoimmune inflammatory diseases.

\section{MATERIALS AND METHODS}

\section{Plant source and extraction}

Petalostigma pubescens Domin and Petalostigma triloculare Mull.Arg. leaves and fruit were collected from single trees in Toohey Forrest, Brisbane, Australia and identified by Dr Ian Cock, Griffith University. The $P$. pubescens tree is located at gps coordinates of $-27^{\circ} 33^{\prime} 15.08^{\prime \prime} \mathrm{S}$, $153^{\circ} 3^{\prime} 18.63^{\prime \prime} \mathrm{E}$ and the P. triloculare tree is located at gps coordinates of $-27^{\circ} 33^{\prime} 15.90^{\prime \prime}$ S, $153^{\circ} 3^{\prime} 10.35^{\prime \prime}$ E. Voucher specimens of all specimens were deposited in the School of Natural Sciences, Griffith University, Australia. Voucher numbers of the $P$. pubescens leaves and fruit specimens are GUPPL-2016-2/10 and GUPPF-2016-2/10 respectively. The voucher numbers of $P$. triloculare leaves and fruit specimens are GUPTL-20162/10 and GUPTF-2016-2/10 respectively. The plant materials were thoroughly dried using a Sunbeam food dehydrator and the materials stored at $-30^{\circ} \mathrm{C}$ until required. Prior to use, the plant materials were thawed and ground into a coarse powder. Individual quantities $(1.5 \mathrm{~g})$ of the ground plant material were weighed into separate tubes and $50 \mathrm{~mL}$ of deionised water, methanol, chloroform, hexane or ethyl acetate were added. All solvents were obtained from Ajax, Australia and were AR grade. The ground plant materials were extracted in each solvent for $24 \mathrm{~h}$ at $4^{\circ} \mathrm{C}$ on an orbital shaker at 20 revolutions per min. The extracts were subsequently filtered through filter paper (Whatman No. 54) under vacuum. The solvent extracts were air dried at room temperature in the shade. The aqueous extracts were lyophilised by freeze drying at $-50^{\circ} \mathrm{C}$. The resultant dried extracts were weighed and dissolved in $10 \mathrm{~mL}$ deionised water (containing $1 \%$ DMSO).

\section{Qualitative phytochemical studies}

Phytochemical analysis of the Petalostigma spp extracts were conducted by modified versions of previously described assays. ${ }^{12,13}$ The modified assays are briefly outlined below.

\section{Alkaloids}

Two methods were used to test for the presence of alkaloids:

\section{Mayers reagent test}

A few drops of aqueous solution of hydrochloric acid and $500 \mu$ l Mayer's reagent was added to $200 \mu \mathrm{L}$ of each extract. Formation of a white precipitate was taken to indicate the presence of alkaloids.

Mayer's reagent: Mercuric chloride (1.358 g) was dissolved in $60 \mathrm{ml}$ deionised water. Potassium Iodide $(5.0 \mathrm{~g})$ was dissolved in $10 \mathrm{ml}$ deionised water. The mercuric chloride and potassium iodide solutions were mixed and made up to $100 \mathrm{ml}$ with deionised water.

\section{Wagners reagent test}

A $200 \mu \mathrm{L}$ volume of each extract was treated with a few drops of dilute hydrochloric acid and $500 \mu \mathrm{L}$ Wagner's reagent. A reddish-brown flocculent precipitate indicated the presence of alkaloid.

Wagner's reagent: $1.27 \mathrm{~g}$ Iodine and $2 \mathrm{~g}$ Potassium Iodide were dissolved in $5 \mathrm{ml}$ deionised water and made up to final volume $100 \mathrm{ml}$ with deionised water.

\section{Anthraquinones}

Free anthraquinones were detected by adding a few drops of concentrated sulphuric acid to $500 \mu \mathrm{L}$ each extract extract, followed by the addition of $500 \mu \mathrm{L}$ of ammonia. A rose-pink colour indicates the presence of free anthraquinones. For combined anthraquinones, $450 \mu \mathrm{L}$ of each extract was individually added to $50 \mu \mathrm{L}$ concentrated $\mathrm{HCl}$. A $500 \mu \mathrm{L}$ volume of chloroform was subsequently added and the colour was noted. The formation of a rose-pink colour indicates the presence of combined anthraquinones.

\section{Cardiac glycosides}

A volume of $500 \mu \mathrm{L}$ of each extract was individually added to $500 \mu \mathrm{L}$ glacial acetic acid. A few drops of $1 \%$ aqueous iron chloride and concentrated sulphuric acid were then carefully added. The presence of a $\mathrm{red} /$ brown ring of the interface or the formation of a green/blue colour throughout the solution indicates the presence of cardiac glycosides.

\section{Flavonoids}

Flavonoids were detected by adding $100 \mu \mathrm{L}$ of aqueous sodium hydroxide to $1 \mathrm{~mL}$ of each extract. The development of an intense yellow colour indicated the presence of flavonoids. A volume of $100 \mu \mathrm{L}$ of concentrated $\mathrm{HCl}$ was subsequently added to the solution. Reversion to the original colour confirmed the presence of flavonoids.

\section{Phenolic compounds}

Phenolic compounds were detected by adding $200 \mu \mathrm{L}$ of extract to $2 \mathrm{~mL}$ of $3 \%$ aqueous sodium carbonate. A volume of $200 \mu \mathrm{L}$ Folin-Ciocalteu reagent was subsequently added and the mixture was allowed to stand for $30 \mathrm{~min}$ at room temperature. The formation of blue/gray colour indicated the presence of phenolic groups. 


\section{Water soluble phenol test}

Two drops of $1 \%$ ferric chloride were added separately to $500 \mu \mathrm{L}$ of the individual extracts. A red colour change indicates presence of watersoluble phenols.

\section{Water insoluble phenol test}

Dichloromethane $(500 \mu \mathrm{L}), 3$ drops of $1 \%$ ferric chloride and 1 drop of pyridine were added to $500 \mu \mathrm{L}$ of each extract in individual tubes and mixed. The presence of insoluble phenols was indicated by a colour change.

\section{Phytosterols}

Phytosterols were detected by adding three drops of acetic anhydride to $500 \mu \mathrm{L}$ of the extracts, followed by the addition of a few drops concentrated sulphuric acid. After 5 min the colour of the solution was noted. Formation of a blue/green colour indicated the presence of phytosterols.

\section{Saponins}

A $1 \mathrm{~mL}$ volume of each extract was added individually to $1 \mathrm{~mL}$ deionised water and shaken vigorously for $30 \mathrm{sec}$. The tubes were allowed to stand for $15 \mathrm{~min}$ and the presence or absence of persistent frothing was noted. Persistent frothing indicated the presence of saponins.

\section{Tannins}

Tannins were detected by adding two drops of $1 \%$ aqueous ferric chloride reagent to $500 \mu \mathrm{L}$ of each extract. Formation of blue, blue-black, green or green-black colouration indicates the presence of tannins.

\section{Triperpenoids}

Triterpenoids were detected by slowly adding $1 \mathrm{~mL}$ of extract to $400 \mu \mathrm{L}$ chloroform, followed by careful addition of $400 \mu \mathrm{L}$ concentrated sulphuric acid. Formation of a red/brown/purple colour at the interface indicated the presence of triterpenoids.

\section{Antibacterial screening \\ Conventional Antibiotics}

Penicillin-G (potency of $1440-1680 \mu \mathrm{g} / \mathrm{mg}$ ), chloramphenicol ( $\geq 98 \%$ purity by HPLC, erythromycin (potency $\geq 850 \mu \mathrm{g} / \mathrm{mg}$ ), gentamicin (potency of $600 \mu \mathrm{g} / \mathrm{mg}$ ) and tetracycline ( $\geq 95 \%$ purity by HPLC) were purchased from Sigma-Aldrich, Australia and used for the microplate liquid dilution assay. All antibiotics were prepared in sterile deionised water at stock concentrations of $0.01 \mathrm{mg} / \mathrm{mL}$ and stored at $4^{\circ} \mathrm{C}$ until use. For the disc diffusion studies, ampicillin $(2 \mu \mathrm{g})$ and chloramphenicol discs $(10 \mu \mathrm{g})$ standard discs were obtained from Oxoid Ltd., Australia and used as positive controls.

\section{Bacterial cultures}

All bacterial strains were selected based on their ability to trigger autoimmune inflammatory diseases in genetically susceptible individuals. ${ }^{12}$ Reference strains of Proteus mirabilis (ATCC21721), Klebsiella pneumoniae (ATCC31488), Acinetobacter baylyi (ATCC33304) and Pseudomonas aeruginosa (ATCC39324) were purchased from American Type Culture Collection, USA. A clinical isolate strain of Streptococcus pyogenes was obtained from the School of Natural Sciences teaching laboratory, Griffith University, Australia. All bacteria were cultured in nutrient broth (Oxoid Ltd., Australia). Streak nutrient agar (Oxoid Ltd., Australia) plates were tested in parallel to ensure the purity of all bacterial cultures and for sub-culturing. All bacterial cultures were incubated at $37^{\circ} \mathrm{C}$ for $24 \mathrm{~h}$ and were subcultured and maintained in nutrient broth at $4^{\circ} \mathrm{C}$ until use.

\section{Evaluation of antibacterial activity}

Antibacterial activity screening of the Petalostigma spp. extracts was assessed using a modified disc diffusion assay. ${ }^{11}$ Ampicillin $(2 \mu \mathrm{g})$ and chloramphenicol discs $(10 \mu \mathrm{g})$ were obtained from Oxoid Ltd., Australia and used as positive controls to compare antibacterial activity. Filter discs infused with $10 \mu \mathrm{L}$ of distilled water were used as a negative control

\section{Minimum inhibitory concentration (MIC) determination}

The minimum inhibitory concentration for each extract was determined using two methods. A liquid dilution MIC assay was employed as it is generally considered the most sensitive bacterial growth inhibitory assay. ${ }^{14}$ Furthermore, as microplate liquid dilution MIC assays are perhaps the most commonly used method of quantifying bacterial growth inhibition efficacy, use of this method allows for comparisons with other studies. A solid phase agar disc diffusion assay was also used in this study for comparison.

\section{Microplate liquid dilution MIC assay}

The MICs of the extracts were evaluated by standard methods. ${ }^{14}$ All plates were incubated at $37^{\circ} \mathrm{C}$ for $24 \mathrm{~h}$. p-Iodonitrotetrazolium violet (INT) was obtained from Sigma-Aldrich, Australia and dissolved in sterile deionised water to prepare a $0.2 \mathrm{mg} / \mathrm{mL}$ INT solution. A $40 \mu \mathrm{L}$ volume of this solution was added into all wells and the plates were incubated for a further $6 \mathrm{~h}$ at $30^{\circ} \mathrm{C}$. Following incubation, the MIC was visually determined as the lowest dose at which colour development was inhibited.

\section{Disc diffusion MIC assay}

The minimum inhibitory concentrations (MIC) of the extracts was also evaluated by disc diffusion assay as previously described. ${ }^{11}$ Graphs of the zone of inhibition versus concentration were plotted and MIC values were achieved using linear regression.

\section{Petalostigma spp. extract-conventional antibiotic synergy studies \\ Fractional inhibitory concentration (FIC) assessment}

Interactions between the Petalostigma spp. extracts and the conventional antibiotics were examined by determination of the sum of fractional inhibitory concentrations ( $\Sigma$ FIC) for each combination. ${ }^{15}$ The FIC values for each component ( $\mathrm{a}$ and $\mathrm{b}$ ) were calculated using the following equations where a represents the plant extract sample and b represents the conventional antibiotic:

$$
\begin{aligned}
& \operatorname{FIC}(a)=\left(\frac{\text { MIC }[\mathrm{a} \text { in combination with } \mathrm{b}]}{\mathrm{MIC}[\mathrm{a} \text { independently }]}\right) \\
& \operatorname{FIC}(\mathrm{b})=\left(\frac{\text { MIC }[\mathrm{b} \text { in combination with } \mathrm{a}]}{\mathrm{MIC}[\mathrm{b} \text { independently }]}\right)
\end{aligned}
$$

The $\Sigma$ FIC was then calculated using the formula $\Sigma F I C=F I C(a)+F I C(b)$. The interactions were classified as synergistic $(\Sigma \mathrm{FIC} \leq 0.5)$, additive $(\Sigma \mathrm{FIC}$ $>0.5-1.0)$, indifferent $(\Sigma \mathrm{FIC}>1.0-4.0)$ or antagonistic $(\Sigma \mathrm{FIC}>4.0) .{ }^{15}$

\section{Varied ratio combination studies (isobolograms)}

For each combination producing synergistic interactions, nine different ratios spanning the range 10:90 (extract: antibiotic) to 90:10 (extract: antibiotic) were tested to determine the ideal ratios to induce synergy. All combinations were tested in duplicate in two independent experiments, providing four replicates for each combination ratio. The data is presented as the mean of four replicates. Data points for each ratio 
examined were plotted on a isobologram and this was used to determine optimal combination ratios to obtain synergy. Data points on or below the 0.5:0.5 line indicated synergy; those above the 0.5:0.5 line, up to and including the 1.0:1.0 line indicated an additive interaction; data points above the 1.0:1.0 line indicated indifferent interaction.

\section{Toxicity screening}

Two assays were used to assess the toxicity of the individual samples. The Artemia lethality assay (ALA) was utilised for rapid preliminary toxicity screening, whereas the MTT cellular proliferation assay was used to determine a cellular evaluation of toxicity.

\section{Artemia franciscana Kellogg nauplii toxicity screening}

Potassium dichromate $\left(\mathrm{K}_{2} \mathrm{Cr}_{2} \mathrm{O}_{7}\right)$ (AR grade, Chem-Supply, Australia) was prepared in deionised water $(4 \mathrm{mg} / \mathrm{mL})$ and serially diluted in artificial seawater as a reference toxin. Toxicity of the Petalostigma spp. extracts, reference toxin and conventional antibiotics was assessed using a modified Artemia franciscana nauplii lethality assay. ${ }^{15,16}$ The $\mathrm{LC}_{50}$ with $95 \%$ confidence limits for each treatment was calculated using probit analysis.

\section{Cellular viability assay}

All Petalostigma spp. extracts and conventional antibiotics were screened individually towards normal human primary dermal fibroblasts (HDF). The HDF cells were obtained from American Type Culture Collection (ATCC PCS-201-012) and were cultured and maintained in Dulbecco's modified eagle medium (DMEM; ThermoFisher Scientific, Australia), supplemented with $10 \%$ foetal calf serum (Life Technologies), $50 \mu \mathrm{g} / \mathrm{mL}$ streptomycin (Sigma-Aldrich, Australia) and $50 \mathrm{IU} / \mathrm{mL}$ penicillin (Sigm-Aldricha, Australia). The cells were maintained as monolayers in $75 \mathrm{~mL}$ flasks at $37^{\circ} \mathrm{C}, 5 \% \mathrm{CO}_{2}$ in a humidified atmosphere until approximately $80 \%$ confluent. Once confluency was achieved, $1 \mathrm{~mL}$ of trypsin (Sigma, Australia) was added to the culture flasks and incubated at $37^{\circ} \mathrm{C}$, $5 \% \mathrm{CO}_{2}$ for $15 \mathrm{~min}$ to dislodge the HDF cells. The cell suspensions were then transferred to a $10 \mathrm{~mL}$ centrifuge tube and sedimented by centrifugation. The supernatant was discarded and the cells were resuspended in $9 \mathrm{~mL}$ of fresh media (lacking streptomycin and penicillin supplementation). Aliquots of the resuspended cells $(70 \mu \mathrm{L}$, containing approximately 5000 cells) were added to individual wells of a 96 well plate. A volume of $30 \mu \mathrm{L}$ of the test extracts or cell media (for the negative control) was added to individual wells and the plates were incubated at $37^{\circ} \mathrm{C}, 5 \% \mathrm{CO}_{2}$ for $24 \mathrm{~h}$ in a humidified atmosphere. All extracts were screened at $200 \mu \mathrm{g} / \mathrm{mL}$. The cells were then washed in PBS ( $\mathrm{pH}$ 7.2) to remove interference due to sample colour. A volume of $20 \mu \mathrm{L}$ of Cell Titre 96 Aqueous One solution (Promega) was subsequently added to each well and the plates were incubated for a further $3 \mathrm{~h}$. Absorbances were recorded at a test wavelength of $540 \mathrm{~nm}$ and a blank wavelength of $690 \mathrm{~nm}$ using a Molecular Devices, Spectra Max M3 plate reader. All tests were performed in at least triplicate and triplicate controls were included on each plate. The $\%$ cellular viability of each test was calculated using the following formula:

$\%$ cellular viability $=\frac{\text { Abs test sample }-(\text { mean Abs control }- \text { mean Abs blank })}{(\text { mean Abs control }- \text { mean Abs blank })}$

Cellular viability $\leq 50 \%$ of the untreated control indicated toxicity, whereas extracts or controls with $>50 \%$ untreated control viability were deemed to be nontoxic.

\section{Statistical analysis}

Data is expressed as the mean \pm SEM of at least three independent experiments. One-way ANOVA was used to calculate statistical significance between the negative control and treated groups with a $P$ value $<0.01$ considered to be statistically significant.

\section{RESULTS}

\section{Liquid extraction yields and qualitative phytochemical screening}

Extractions of the Petalostigma spp. plant materials ( $1.5 \mathrm{~g}$ ) with solvents of varying polarity yielded dried plant extracts ranging from $93 \pm 4 \mathrm{mg}$ ( $P$. pubescens fruit ethyl acetate extract) to $768 \pm 10 \mathrm{mg}$ (P. pubescens fruit methanolic extract) (Table 1). Qualitative phytochemical screening (Table 1) showed that the higher polarity solvents (methanol and water) extracted the greatest amount and widest diversity of phytochemical classes.

\section{Bacterial growth inhibition screening Inhibition of a bacterial trigger of rheumatoid arthritis ( $P$. mirabilis)}

With some notable exceptions, $P$. mirabilis growth was particularly susceptible to the higher polarity aqueous and methanolic Petalostigma spp. extracts (Figure 1). The aqueous Petalostigma spp. leaf extracts were the exception to this trend, with only small zones of inhibition recorded. $P$. pubescens aqueous fruit extract was the best inhibitor of $P$. mirabilis growth, with a zone of inhibition of $18.4 \pm 0.5 \mathrm{~mm}$ measured. Notably, both the $P$. pubescens aqueous and methanolic fruit extracts $(17.9 \pm 0.5 \mathrm{~mm})$ produced larger zones of inhibition than the ampicillin $(16.9 \pm 0.4 \mathrm{~mm})$ and chloramphenicol controls $(16.5 \pm 0.6 \mathrm{~mm}$ ) (Figure 1a). P. pubescens fruit and $P$. triloculare leaf ethyl acetate extracts were also moderate inhibitors of $P$. mirabilis growth.

\section{Inhibition of a bacterial trigger of ankylosing spondylitis (K. pneumoniae)}

All Petalostigma spp. extracts inhibited the growth of K. pneumoniae (Figure 2) albeit, generally with lower efficacy than for P. mirabilis growth inhibition. With the exception of the aqueous $P$. triloculare leaf extract, the higher polarity aqueous and methanolic extracts were good growth inhibitors (inhibition zones $>10 \mathrm{~mm}$ ). The methanolic $P$. triloculare leaf extract was the best growth inhibitor, with an inhibition zone of $14 \mathrm{~mm}$. This is noteworthy as this K. pneumoniae strain is resistant to $\beta$-lactam antibiotics (as evident from the low zone of inhibition seen for ampicillin in Figure 2). Indeed, the ampicillin zone of inhibition was not significantly different to that of the negative control. In contrast, this bacterium was highly susceptible to chloramphenicol, with an inhibition zone of $22 \pm 0.9 \mathrm{~mm}$. The growth inhibition recorded for the lower polarity chloroform, hexane and ethyl acetate extracts were significantly lower than for the polar extracts. In total, 17 of the 20 Petalostigma spp. extracts induce larger zones of inhibition than seen for the ampicillin control.

\section{Inhibition of bacterial triggers of multiple sclerosis (A. baylyi and P. aeruginosa)}

The aqueous and methanolic extracts (with the exception of the aqueous Petalostigma spp. leaf extracts) were potent inhibitors of A. baylyi growth (Figure 3). The methanolic P. pubescens fruit extract was the most potent inhibitor of $A$. baylyi growth $(18.4 \pm 0.5 \mathrm{~mm})$. Indeed, the inhibition zones produced by this extract were comparable with those of the chloramphenicol control and substantially higher than the ampicillin control. Similarly, the aqueous $P$. pubescens fruit extract was a good inhibitor of A. baylyi growth, with a zone of inhibition of $18.1 \pm 0.7 \mathrm{~mm}$. The aqueous and methanolic $P$. triloculare fruit extracts and the methanolic $P$. triloculare leaf extract inhibited the growth of $A$. baylyi with substantially greater efficacy than the ampicillin control, with zones of inhibition $>15 \mathrm{~mm}$ 


\begin{tabular}{|c|c|c|c|c|c|c|c|c|c|c|c|c|c|c|c|c|}
\hline & 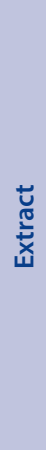 & 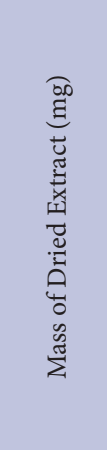 & 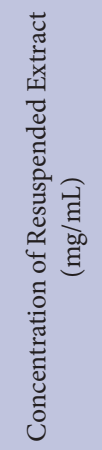 & 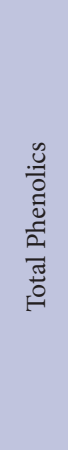 & 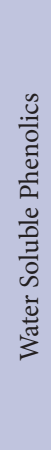 & 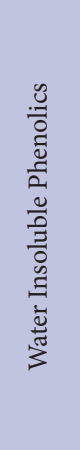 & 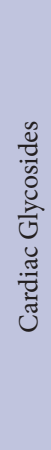 & 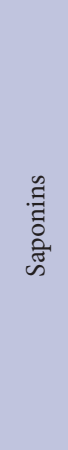 & 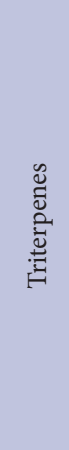 & 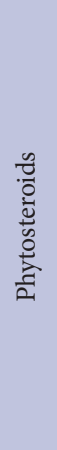 & 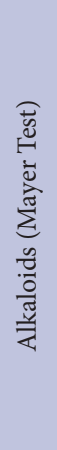 & 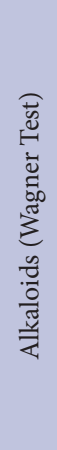 & 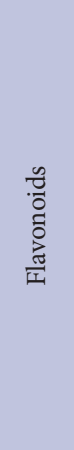 & $\begin{array}{l}\stackrel{\Xi}{\Xi} \\
\text { స్ }\end{array}$ & 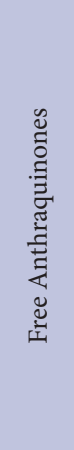 & 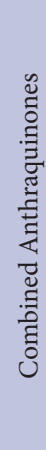 \\
\hline \multirow{5}{*}{ 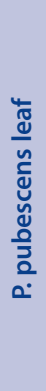 } & w & $270 \pm 5$ & $27 \pm 1$ & +++ & - & +++ & - & ++ & ++ & - & - & - & ++ & +++ & ++ & - \\
\hline & $M$ & $460 \pm 6$ & $46 \pm 1$ & +++ & - & +++ & - & ++ & +++ & - & ++ & ++ & ++ & +++ & ++ & - \\
\hline & C & $200 \pm 4$ & $20 \pm 1$ & + & - & - & - & - & - & - & - & - & ++ & - & - & - \\
\hline & $\mathrm{H}$ & $103 \pm 3$ & $10 \pm 1$ & + & - & + & - & +++ & - & - & - & - & ++ & - & - & - \\
\hline & $E$ & $200 \pm 3$ & $200 \pm 1$ & +++ & - & +++ & - & - & + & - & - & - & +++ & +++ & ++ & - \\
\hline \multirow{5}{*}{ 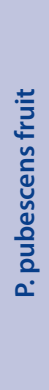 } & w & $615 \pm 6$ & $62 \pm 1$ & +++ & - & +++ & - & + & +++ & - & - & - & ++ & +++ & ++ & - \\
\hline & $M$ & $768 \pm 10$ & $77 \pm 1$ & +++ & - & +++ & - & + & +++ & + & - & - & +++ & +++ & ++ & - \\
\hline & C & $143 \pm 7$ & $14 \pm 1$ & - & - & + & - & - & - & - & - & - & ++ & - & - & - \\
\hline & $\mathrm{H}$ & $110 \pm 5$ & $11 \pm 1$ & ++ & - & +++ & - & - & - & - & ++ & - & ++ & + & +++ & - \\
\hline & $E$ & $93 \pm 4$ & $9 \pm 1$ & +++ & - & ++ & - & + & ++ & - & - & - & +++ & ++ & ++ & - \\
\hline \multirow{5}{*}{ 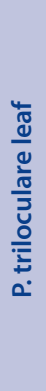 } & w & $543 \pm 7$ & $54 \pm 1$ & +++ & - & +++ & - & +++ & +++ & - & - & - & - & +++ & ++ & - \\
\hline & $M$ & $263 \pm 2$ & $26 \pm 1$ & +++ & - & +++ & - & +++ & +++ & - & - & - & ++ & +++ & ++ & - \\
\hline & C & $190 \pm 4$ & $19 \pm 1$ & + & - & + & - & - & - & - & - & - & ++ & - & - & - \\
\hline & $\mathrm{H}$ & $163 \pm 7$ & $16 \pm 1$ & + & - & + & - & + & - & - & - & - & ++ & - & - & - \\
\hline & $E$ & $217 \pm 7$ & $22 \pm 1$ & +++ & - & +++ & - & - & - & - & - & - & +++ & +++ & ++ & - \\
\hline \multirow{5}{*}{ 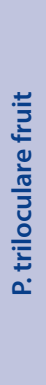 } & w & $633 \pm 4$ & $63 \pm 1$ & +++ & - & +++ & - & - & +++ & ++ & - & - & - & +++ & ++ & - \\
\hline & $M$ & $698 \pm 8$ & $70 \pm 1$ & +++ & - & +++ & - & + & +++ & ++ & - & - & +++ & +++ & ++ & - \\
\hline & C & $185 \pm 6$ & $19 \pm 1$ & + & - & +++ & - & - & - & - & - & - & ++ & - & - & - \\
\hline & $\mathrm{H}$ & $115 \pm 4$ & $12 \pm 1$ & +++ & - & ++ & - & - & - & ++ & - & - & +++ & +++ & ++ & - \\
\hline & E & $120 \pm 6$ & $12 \pm 1$ & +++ & - & ++ & - & - & - & + & - & - & +++ & +++ & ++ & - \\
\hline
\end{tabular}




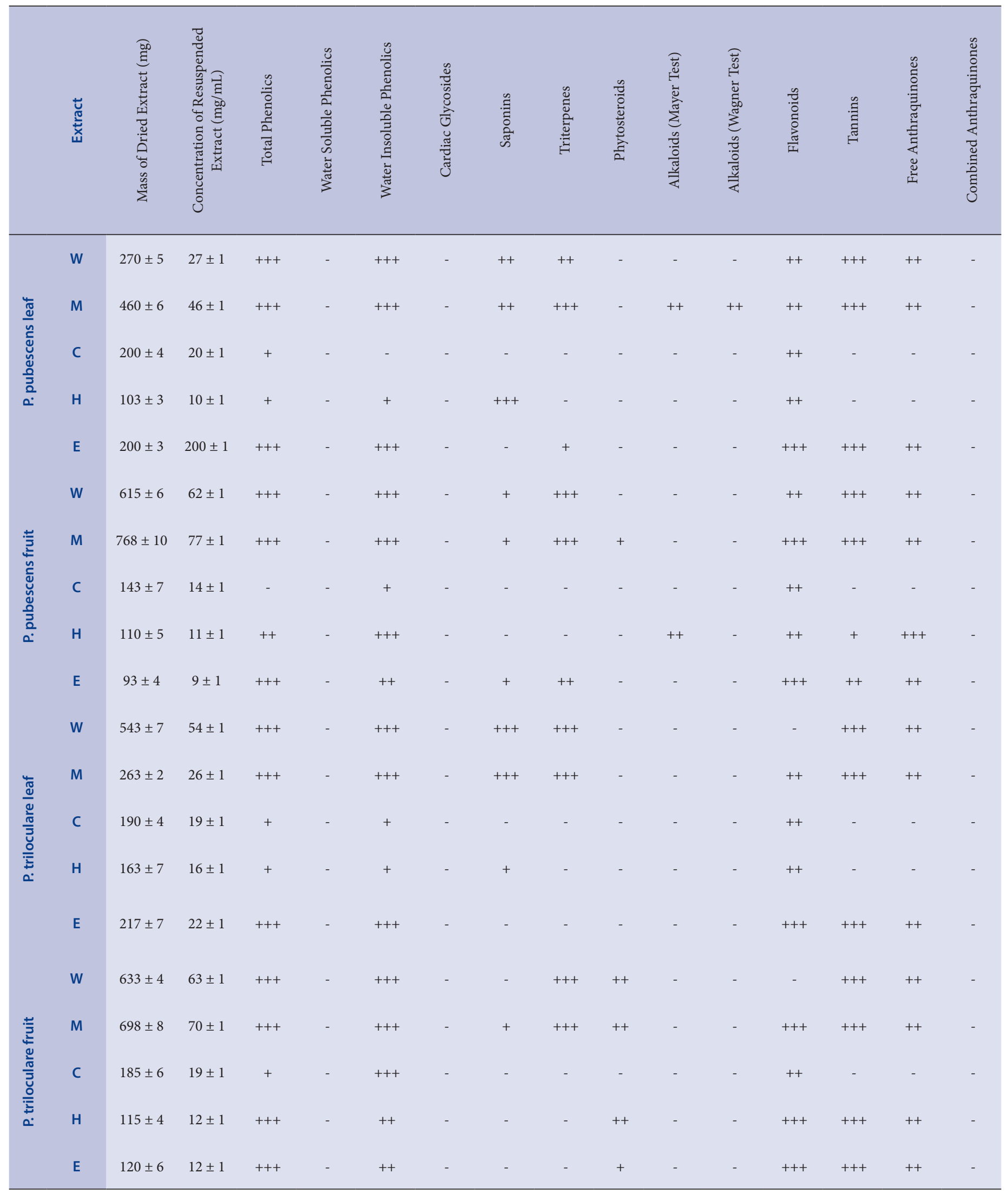

+++ indicates a large response; ++ indicates a moderate response; + indicates a minor response; - indicates no response in the assay. $\mathrm{W}=$ aqueous extract; $\mathrm{M}=$ methanolic extract; $\mathrm{C}=$ chloroform extract; $\mathrm{H}=$ hexane extract; $\mathrm{E}=$ ethyl acetate extract. 


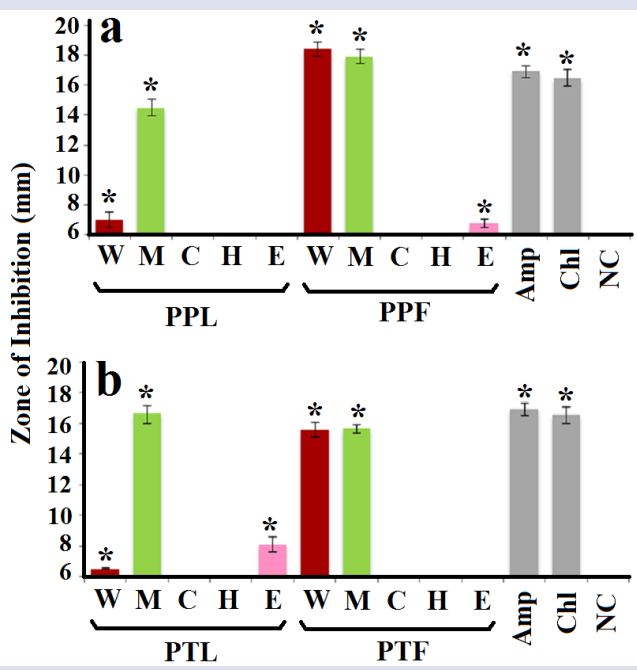

Figure 1: Antibacterial activity of $P$. pubescens (a) and $P$. triloculare (b) fruit and leaf extracts against $P$. mirabilis (ATCC: 21721 ) measured as zones of inhibition $(\mathrm{mm}) . \mathrm{PP}=P$. pubescens; $\mathrm{PT}=P$. triloculare; $\mathrm{L}=$ leaf; $\mathrm{F}=$ fruit; $\mathrm{W}=$ aqueous extract; $\mathrm{M}=$ methanolic extract; $\mathrm{C}=$ chloroform extract; $\mathrm{H}=$ hexane extract; $\mathrm{E}=$ ethyl acetate extract. Positive control

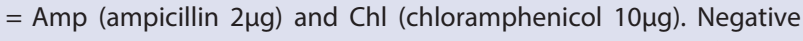
control (NC) = water. Results are expressed as mean zones of inhibition of at least six replicates (two repeats) \pm SEM. ${ }^{*}$ indicates results that are significantly different to the negative control $(P<0.01)$

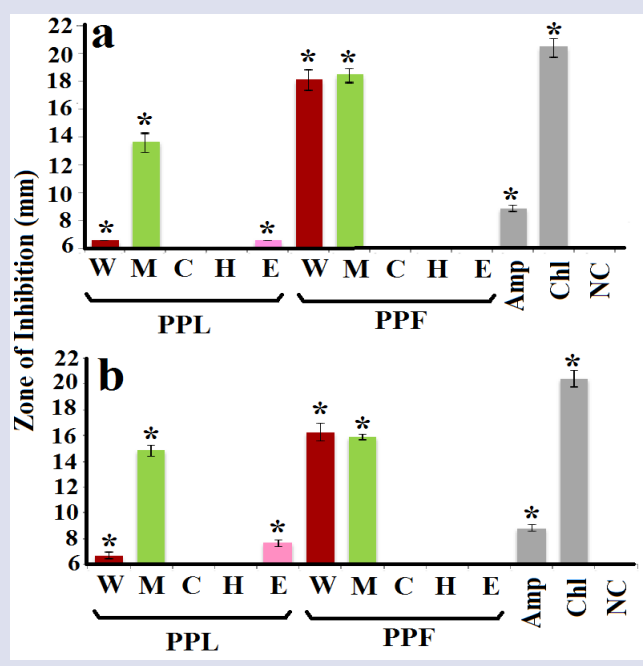

Figure 3: Antibacterial activity of $P$. pubescens (a) and $P$. triloculare (b) fruit and leaf extracts against $A$. baylyi (ATCC: 33304 ) measured as zones of inhibition $(\mathrm{mm}) . \mathrm{PP}=P$. pubescens; $\mathrm{PT}=P$. triloculare $\mathrm{L}=$ leaf; $\mathrm{F}=$ fruit; $\mathrm{W}=$ aqueous extract; $\mathrm{M}=$ methanolic extract; $\mathrm{C}=$ chloroform extract; $\mathrm{H}=$ hexane extract; $\mathrm{E}=$ ethyl acetate extract. Positive control

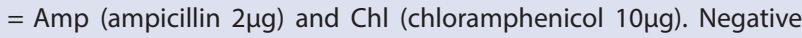
control (NC) = water. Results are expressed as mean zones of inhibition of at least six replicates (two repeats) \pm SEM. ${ }^{*}$ indicates results that are significantly different to the negative control $(P<0.01)$.

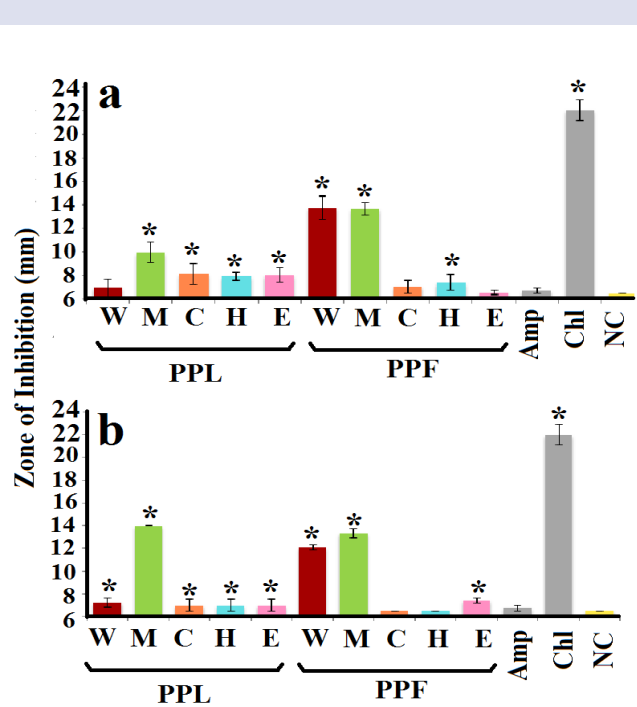

Figure 2: Antibacterial activity of $P$. pubescens (a) and $P$. triloculare (b) fruit and leaf extracts against $K$. pneumoniae (ATCC: 31488 ) measured as zones of inhibition $(\mathrm{mm}) . \mathrm{PP}=P$. pubescens; $\mathrm{PT}=P$. triloculare; $\mathrm{L}=$ leaf; $\mathrm{F}=$ fruit; $\mathrm{W}=$ aqueous extract; $\mathrm{M}=$ methanolic extract; $\mathrm{C}=$ chloroform extract; $\mathrm{H}=$ hexane extract; $\mathrm{E}=$ ethyl acetate extract. Positive control $=$ Amp (ampicillin $2 \mu \mathrm{g}$ ) and Chl (chloramphenicol 10 $\mu \mathrm{g}$ ). Negative control (NC) = water. Results are expressed as mean zones of inhibition of at least six replicates (two repeats) \pm SEM. ${ }^{*}$ indicates results that are significantly different to the negative control $(P<0.01)$. (compared to $8.8 \pm 0.3 \mathrm{~mm}$ for the ampicillin control) (Figure 3b). With the exception of the ethyl acetate Petalostigma spp. leaf extracts, all of the less polar (hexane, chloroform and ethyl acetate) extracts were completely devoid of A. baylyi growth inhibitory activity.

With the exception of $P$. pubescens fruit ethyl acetate and $P$. triloculare fruit hexane extracts, all extracts inhibited the growth of $P$. aeruginosa (Figure 4). The $P$. pubescens fruit methanolic extract was the best inhibitor of $P$. aeruginosa growth, with a zone of inhibition of $16 \pm 0.5 \mathrm{~mm}$. This was particularly noteworthy as the $P$. aeruginosa strain tested in this study was resistant to both the ampicillin and chloramphenicol controls, each inducing only $6.5 \mathrm{~mm}$ zones of inhibition. Furthermore, the methanolic and aqueous extracts of Petalostigma spp. fruit and the methanolic $P$. triloculare leaf extract also had zones of inhibition $>12 \mathrm{~mm}$. Notably, all of the $P$. pubescens leaf extracts (including the less polar hexane, chloroform and ethyl acetate extracts) had zones of inhibition $>7 \mathrm{~mm}$. Our studies therefore indicate that the methanolic $P$. pubescens fruit extract was the most effective inhibitor of both bacterial triggers of multiple sclerosis.

\section{Inhibition of the bacterial trigger of rheumatic fever (S. pyogenes)}

All $P$. pubescens extracts inhibited $S$. pyogenes growth (Figure 5a). Similarly, with the exception of the chloroform and hexane extracts, all of the $P$. triloculare extracts also inhibited the growth of $S$. pyogenes, albeit often with lower efficacies (Figure 5b). The aqueous Petalostigma spp. fruit extracts were substantially better $S$. pyogenes growth inhibitors $(>12 \mathrm{~mm}$ zones of inhibition) compared to the corresponding leaf extracts. The methanolic $P$. triloculare leaf extract was the strongest 


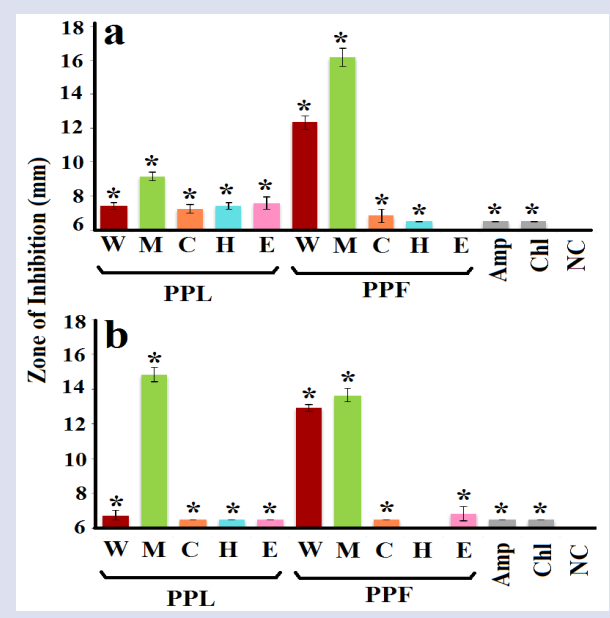

Figure 4: Antibacterial activity of $P$. pubescens (a) and $P$. triloculare (b) fruit and leaf extracts against $P$. aeruginosa (ATCC: 39324 ) measured as zones of inhibition (mm). $\mathrm{PP}=P$. pubescens; $\mathrm{PT}=P$. triloculare; $\mathrm{L}=$ leaf; $\mathrm{F}=$ fruit; $\mathrm{W}=$ aqueous extract; $\mathrm{M}=$ methanolic extract; $\mathrm{C}=$ chloroform extract; $\mathrm{H}=$ hexane extract; $\mathrm{E}=$ ethyl acetate extract. Positive control

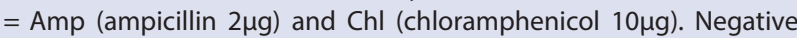
control (NC) = water. Results are expressed as mean zones of inhibition of at least six replicates (two repeats) \pm SEM. ${ }^{*}$ indicates results that are significantly different to the negative control $(P<0.01)$.

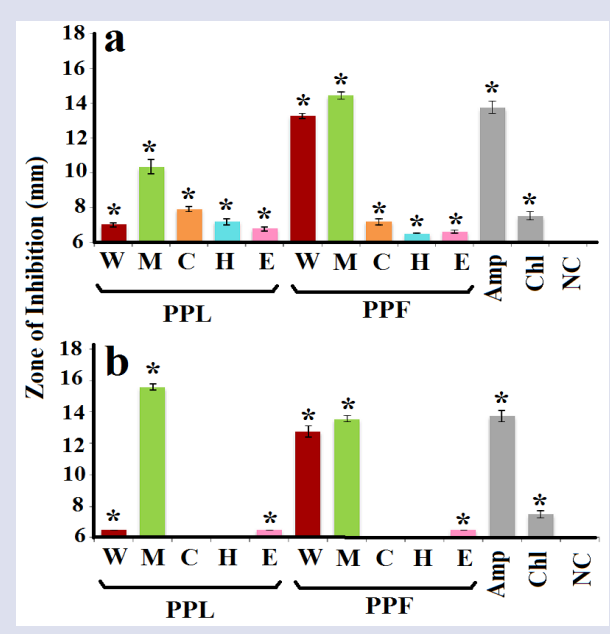

Figure 5: Antibacterial activity of $P$. pubescens (a) and $P$. triloculare (b) fruit and leaf extracts against a clinical isolate of $S$. pyogenes measured as zones of inhibition $(\mathrm{mm}) . \mathrm{PP}=P$. pubescens; $\mathrm{PT}=P$. triloculare; $\mathrm{L}=$ leaf; $\mathrm{F}=$ fruit; $\mathrm{W}=$ aqueous extract; $\mathrm{M}=$ methanolic extract; $\mathrm{C}=$ chloroform extract; $\mathrm{H}=$ hexane extract; $\mathrm{E}=$ ethyl acetate extract. Positive control = Amp (ampicillin $2 \mu \mathrm{g}$ ) and Chl (chloramphenicol 10 $\mu \mathrm{g}$ ). Negative control $(\mathrm{NC})=$ water. Results are expressed as mean zones of inhibition of at least six replicates (two repeats) \pm SEM. ${ }^{*}$ indicates results that are significantly different to the negative control $(P<0.01)$. inhibitor of S. pyogenes growth with an inhibition zone of $15.6 \pm 0.5 \mathrm{~mm}$. The methanolic $P$. pubescens fruit extract was similarly potent (14.4 \pm $0.5 \mathrm{~mm}$ ). Indeed, the methanolic extracts of both the P. triloculare leaf and the $P$. pubescens fruit had greater relative activity than the ampicillin $(13.8 \pm 0.9 \mathrm{~mm})$ and chloramphenicol controls $(7.5 \pm 0.6 \mathrm{~mm})$.

\section{Quantification of minimum inhibitory concentration (MIC)}

The relative level of antimicrobial activity was further evaluated by determining the MIC values using two methods: the liquid dilution MIC assay and the disc diffusion MIC assay (Table 2). Consistent with the antibacterial screening assays, each of the higher polarity methanol and water Petalostigma spp. extracts inhibited all of the bacteria tested and were more potent in comparison to the corresponding less polar extracts. The MIC values of the conventional antibiotic controls were only determined for the liquid dilution assay. Commercially manufactured discs with set amounts of antibiotics loaded were used for the disc diffusion assay and thus the zones of only single doses was recorded for the disc diffusion MIC assay. Gentamicin was the most potent antibiotic (as judged by its MIC) and inhibited the widest range of bacterial species. Notably, the $P$. aeruginosa strain used in these studies was particularly resistant to all of antibiotics, with the exception of gentamicin. Furthermore, with the exception of $P$. mirabilis, all of the other bacterial strains were resistant to penicillin.

The MIC values determined for the Petalostigma spp. extracts compare relatively well between the disc diffusion and liquid dilution assays with a few notable exceptions e.g. inhibition of $S$. pyogenes growth by P. triloculare leaf aqueous (DD $>10000 \mu \mathrm{g} / \mathrm{mL} ; \mathrm{LD} 344 \mu \mathrm{g} / \mathrm{mL}$ ). All bacterial species were generally more susceptible to $P$. pubescens fruit than to $P$. triloculare fruit extracts (based on MIC values). In contrast, P. pubescens and P. triloculare leaf extracts had similar levels of antimicrobial activity. The growth of $P$. mirabilis was inhibited by methanolic P. pubescens leaf (DD MIC $1329 \mu \mathrm{g} / \mathrm{mL}$; LD MIC $1469 \mu \mathrm{g} / \mathrm{mL}$ ) and fruit extracts (DD MIC $1069 \mu \mathrm{g} / \mathrm{mL}$; LD MIC $2594 \mu \mathrm{g} / \mathrm{mL}$ ) and by the methanolic P. triloculare leaf extract (DD MIC $1273 \mu \mathrm{g} / \mathrm{mL}$; LD MIC $1500 \mu \mathrm{g} / \mathrm{mL}$ ), although these values indicate only low to moderate activity. Aqueous $P$. pubescens fruit and $P$. triloculare leaf extracts were moderate inhibitors of $P$. mirabilis growth. Aqueous $P$. pubescens leaf (DD MIC $>10000 \mu \mathrm{g} / \mathrm{mL}$; LD MIC $750 \mu \mathrm{g} / \mathrm{mL}$ ) and $P$. triloculare leaf extracts (DD MIC $2940 \mu \mathrm{g} / \mathrm{mL}$; LD MIC $750 \mu \mathrm{g} / \mathrm{mL}$ ) were also moderate $K$. pneumoniae growth inhibitors. $P$. pubescens leaf ethyl acetate and $P$. triloculare leaf methanolic extracts were also moderate $K$. pneumoniae growth inhibitors. Similarly, the growth of A. baylyi was inhibited by methanolic extracts of $P$. pubescens fruit (DD MIC $1313 \mu \mathrm{g} / \mathrm{mL}$; LD MIC $2594 \mu \mathrm{g} / \mathrm{mL}$ ), P. triloculare leaf (DD MIC $1441 \mu \mathrm{g} / \mathrm{mL}$; LD MIC $3000 \mu \mathrm{g} / \mathrm{mL}$ ) and the aqueous $P$. pubescens fruit extract (DD MIC $1687 \mu \mathrm{g} / \mathrm{mL}$; LD MIC $3938 \mu \mathrm{g} / \mathrm{mL}$ ) with low to moderate potency. The strongest growth inhibitor of $P$. aeruginosa was the methanolic P. pubescens fruit extract (DD MIC $6757 \mu \mathrm{g} / \mathrm{mL}$; LD MIC $2406 \mu \mathrm{g} / \mathrm{mL}$ ), although these values indicate only low potency. Similarly, the aqueous P. triloculare leaf, methanolic P. pubescens leaf (DD MIC $1843 \mu \mathrm{g} / \mathrm{mL}$; LD MIC $750 \mu \mathrm{g} / \mathrm{mL}$ ), methanolic P. pubescens fruit (DD MIC $1247 \mu \mathrm{g} / \mathrm{mL}$; LD MIC $656 \mu \mathrm{g} / \mathrm{mL}$ ) and methanolic P. triloculare leaf extracts (DD MIC $1969 \mu \mathrm{g} / \mathrm{mL}$; LD MIC $453 \mu \mathrm{g} / \mathrm{mL}$ ) were also moderate growth inhibitors of $S$. pyogenes growth.

\section{Fractional inhibitory concentration (FIC) assessment Combinational effects on a bacterial trigger of rheumatoid arthritis (P. mirabilis)}

A wide range of interactions was evident for combinations of the Petalostigma spp. extracts with conventional antibiotics when tested against $P$. mirabilis (Table 3). Approximately $18 \%$ of the combinations 
Table 2: Disc diffusion and liquid dilution MIC values for $P$. pubescens and $P$. triloculare fruit and leaf extracts against $P$. mirabilis, $K$. pneumoniae, A. baylyi, P. aeruginosa and S. pyogenes growth $(\mu \mathrm{g} / \mathrm{mL})$.

\begin{tabular}{|c|c|c|c|c|c|c|c|c|c|c|}
\hline \multirow[t]{2}{*}{ EXRACT } & \multicolumn{2}{|c|}{$\begin{array}{l}\text { P. mirabilis } \\
\text { (ATCC: } 33304 \text { ) }\end{array}$} & \multicolumn{2}{|c|}{$\begin{array}{l}\text { K. pneumoniae } \\
\text { (ATCC: 31488) }\end{array}$} & \multicolumn{2}{|c|}{$\begin{array}{c}\text { A. baylyi } \\
\text { (ATCC: 21721) }\end{array}$} & \multicolumn{2}{|c|}{$\begin{array}{l}\text { P. aeruginosa } \\
\text { (ATCC: 39324) }\end{array}$} & \multicolumn{2}{|c|}{ S. pyogenes } \\
\hline & DD MIC & LD MIC & DD MIC & LD MIC & DD MIC & LD MIC & DD MIC & LD MIC & DD MIC & LD MIC \\
\hline PLW & $>10000$ & 3000 & $>10000$ & 750 & $>10000$ & 3000 & 8918 & 3250 & 6504 & 1810 \\
\hline PLM & 1329 & 1469 & 4627 & 2938 & 2049 & 2938 & 8994 & 3000 & 1843 & 750 \\
\hline PLC & - & - & $>10000$ & - & - & - & 5986 & - & 2189 & 5250 \\
\hline PLH & - & - & $>10000$ & - & - & - & 3430 & - & 2079 & - \\
\hline PLE & - & 6000 & 6022 & 1500 & $>10000$ & 2000 & 5442 & 6000 & $>10000$ & 2250 \\
\hline PFW & 1478 & 3938 & 2214 & 3938 & 1687 & 3938 & 4741 & 3940 & 2128 & 3938 \\
\hline PFM & 1069 & 2594 & 2183 & 2594 & 1313 & 2594 & 6757 & 2406 & 1247 & 656 \\
\hline PFC & - & - & 5225 & - & - & - & $>10000$ & - & $>10000$ & - \\
\hline PFH & - & - & 3430 & - & - & - & $>10000$ & - & $>10000$ & - \\
\hline PFE & 8000 & 2000 & 8000 & - & - & - & - & - & 8000 & 1500 \\
\hline TLW & $>10000$ & 1500 & 2940 & 750 & 2832 & 3000 & $>10000$ & 8000 & $>10000$ & 344 \\
\hline TLM & 1273 & 1500 & 2812 & 1500 & 1441 & 3000 & 3287 & 3688 & 1969 & 453 \\
\hline TLC & - & - & 4503 & - & - & - & $>10000$ & - & - & - \\
\hline TLH & - & - & 3752 & - & - & - & $>10000$ & - & - & 4000 \\
\hline TLE & $>10000$ & 5250 & 4002 & 5250 & 5994 & - & $>10000$ & - & $>10000$ & 1500 \\
\hline TFW & 3879 & 4625 & $>10000$ & 9250 & 4385 & 9250 & $>10000$ & 4438 & 8138 & 2344 \\
\hline TFM & 2382 & 5313 & 5127 & $>10000$ & 4416 & 5313 & 7558 & 2500 & 5253 & 2563 \\
\hline TFC & - & - & $>10000$ & - & - & - & $>10000$ & - & - & - \\
\hline TFH & - & - & $>10000$ & - & - & - & - & - & - & 3250 \\
\hline TFE & - & - & $>10000$ & - & - & - & $>10000$ & - & $>10000$ & 3500 \\
\hline \multicolumn{11}{|l|}{ Positive controls } \\
\hline Penicillin & ND & 2.5 & ND & - & ND & - & ND & - & ND & - \\
\hline Chloramphenicol & ND & - & ND & 1.25 & ND & 2.5 & ND & - & ND & - \\
\hline Gentamicin & ND & 1.25 & ND & 0.31 & ND & 0.31 & ND & 0.63 & ND & 0.63 \\
\hline Erythromycin & ND & - & ND & - & ND & 2.5 & ND & - & ND & - \\
\hline Tetracycline & ND & - & ND & 1.25 & ND & 1.25 & ND & - & ND & 2.5 \\
\hline Negative control & ND & - & ND & - & ND & - & ND & - & ND & - \\
\hline
\end{tabular}

$\mathrm{P}=$ P. pubescens $; \mathrm{T}=$ P. triloculare $\mathrm{L}=$ leaf; $\mathrm{F}=$ fruit $\mathrm{W}=$ water $\mathrm{M}=$ methanol $\mathrm{C}=$ chloroform $; \mathrm{H}=$ hexane; $\mathrm{E}=$ ethyl acetate. $\mathrm{DD}=$ disc diffusion; $\mathrm{LD}=$ liquid dilution. indicates no inhibition at any dose tested.

Numbers indicate the mean DD MIC and LD MIC values of triplicate determinations, expressed in $\mu \mathrm{g} / \mathrm{mL}$.

$\mathrm{ND}=$ MIC could not be determined as only a single dose was tested.

produced additive effects, whilst the majority of combinations were non-interactive. Notably, the methanolic P. triloculare leaf extract produced additive interactions with all conventional antibiotic combinations against $P$. mirabilis. However, combinations of gentamicin with either $P$. pubescens leaf ethyl acetate extract $(\Sigma$ FIC $=6)$ or $P$. triloculare leaf hexane extract $(\Sigma \mathrm{FIC}=4.5)$ were antagonistic against $P$. mirabilis growth inhibition. This is noteworthy and indicates that these combinations should be avoided as chemotherapeutic options in the treatment of $P$. mirabilis infections. A total of seven synergistic interactions were observed between Petalostigma spp. extracts and conventional antibiotic combinations. Interestingly, three of these synergies occurred when penicillin-G was combined with the low to mid polarity $P$. pubescens fruit hexane $(\Sigma \mathrm{FIC}=0.31), P$. pubescens fruit ethyl acetate $(\Sigma \mathrm{FIC}=0.50)$ and $P$. triloculare leaf ethyl acetate extracts $(\Sigma$ FIC $=0.50)$. Similarly, combinations of chloramphenicol with $P$. pubescens fruit hexane $(\Sigma \mathrm{FIC}=0.25), P$. triloculare leaf hexane $(\Sigma \mathrm{FIC}=0.25)$ and $P$. triloculare leaf ethyl acetate extracts $(\Sigma$ FIC $=0.31$ ) also resulted in synergy. The combination of $P$. pubescens fruit hexane extract and erythromycin also proved synergistic against the growth of $P$. mirabilis $(\Sigma$ FIC $=0.25)$. Therefore, a general trend was noted: most synergies occurred either with penicillin or chloramphenicol when in combination with lower polarity extracts against $P$. mirabilis. This contrasts with the earlier studies into the growth inhibitory activity of the Petalostigma spp. alone, where the higher polarity extracts were generally the most potent bacterial growth inhibitors. 
Table 3: $\Sigma$ FIC values of Petalostigma spp. extracts in combination with conventional antibiotics against $P$. mirabilis (ATCC 21721).

\begin{tabular}{|c|c|c|c|c|c|}
\hline & 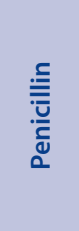 & 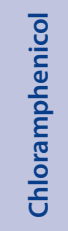 & 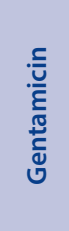 & 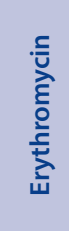 & 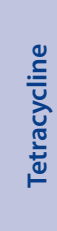 \\
\hline PLW & 1.50 & 0.56 & 2.00 & 1.13 & 1.13 \\
\hline PLM & 1.13 & 1.03 & 1.25 & 1.03 & 1.03 \\
\hline PLC & 2.50 & - & 1.13 & - & - \\
\hline PLH & 2.50 & - & 1.13 & - & - \\
\hline PLE & - & 0.63 & 6.00 & 2.50 & 2.50 \\
\hline PFW & 1.25 & 1.06 & 1.50 & 1.06 & 1.06 \\
\hline PFM & 1.13 & 0.52 & 0.63 & 0.52 & 0.52 \\
\hline PFC & 2.50 & - & 0.84 & - & - \\
\hline PFH & 0.31 & 0.25 & 1.13 & 0.25 & - \\
\hline PFE & 0.50 & 0.63 & 1.50 & 2.50 & 2.50 \\
\hline TLW & 1.25 & 1.06 & 1.50 & 1.06 & 1.06 \\
\hline TLM & 0.56 & 0.52 & 0.63 & 0.52 & 0.52 \\
\hline TLC & 2.50 & - & 1.13 & - & - \\
\hline TLH & 0.63 & 0.25 & 4.50 & - & - \\
\hline TLE & 0.50 & 0.31 & 1.50 & 0.63 & 0.63 \\
\hline TFW & 1.25 & 1.06 & 1.50 & 1.06 & 1.50 \\
\hline TFM & 1.25 & 1.06 & 1.50 & 1.06 & 1.06 \\
\hline TFC & 0.63 & - & 1.13 & - & - \\
\hline TFH & 2.50 & - & 1.13 & - & - \\
\hline TFE & 0.63 & - & 1.13 & - & - \\
\hline
\end{tabular}

$\mathrm{P}=$ P. pubescens $; \mathrm{T}=$ P. triloculare $\mathrm{L}=$ leaf $\mathrm{F}=$ fruit $\mathrm{W}=$ water $\mathrm{M}=$ methanol; $\mathrm{C}=$ chloroform; $\mathrm{H}=$ hexane; $\mathrm{E}=$ ethyl acetate - indicates that the $\Sigma$ FIC could not be determined.

Synergy $($ bold text $)=\leq 0.5$; Additive (italics) $=>0.5-1.0$; Indifferent (no highlighting $)=>1.0-\leq 4 ;$ Antagonistic $($ underlined text $)=>4.0$

Numbers indicate the mean FIC values of 4 determinations

\section{Combinational effects on a bacterial trigger of ankylosing spondylitis (K. pneumoniae)}

No synergistic interactions were noted for combinations of the Petalostigma spp. extracts and conventional antibiotics against the growth of K. pneumoniae (Table 4). Approximately 13\% of the combinations were additive, indicating that these combinations may still be beneficial due to increased growth inhibitory efficacies. The majority of these additive interactions involved combinations of the less polar chloroform, hexane and ethyl acetate extracts with tetracycline. Interestingly, five of these less polar extracts seemed to be antagonistic when combined with other antibiotics. Chloramphenicol in conjunction with either $P$. pubescens leaf (chloroform and hexane) or P. triloculare leaf chloroform extracts yielded antagonistic interactions. Similarly, gentamicin in combination with hexane and ethyl acetate $P$. triloculare leaf extracts were also antagonistic. Combinations of tetracycline and $P$. triloculare leaf chloroform and hexane extracts also produced antagonistic interactions against $K$. pneumoniae growth inhibition. Thus, these combinations
Table 4: $\Sigma$ FIC values of Petalostigma spp. extracts in combination with conventional antibiotics against $K$. pneumoniae (ATCC 31488).

\begin{tabular}{|c|c|c|c|c|c|}
\hline & 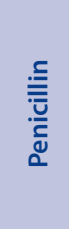 & 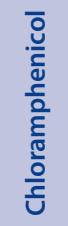 & 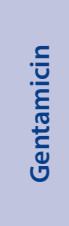 & 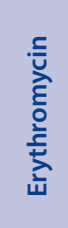 & 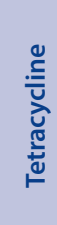 \\
\hline PLW & 1.03 & 1.25 & 2.00 & 1.03 & 1.25 \\
\hline PLM & 1.06 & 1.50 & 3.00 & 1.06 & 1.50 \\
\hline PLC & - & 4.50 & 1.03 & - & 0.56 \\
\hline PLH & - & 4.50 & 1.03 & - & 0.56 \\
\hline PLE & 1.06 & 3.00 & 3.00 & 2.13 & 1.50 \\
\hline PFW & 1.06 & 1.50 & 3.00 & 1.06 & 1.50 \\
\hline PFM & 1.03 & 1.25 & 2.00 & 1.03 & 1.25 \\
\hline PFC & - & 1.13 & 1.03 & - & 0.56 \\
\hline PFH & - & 1.13 & 2.06 & - & 0.56 \\
\hline PFE & - & 1.13 & 2.06 & - & 0.56 \\
\hline TLW & 1.03 & 1.25 & 2.00 & 1.03 & 1.25 \\
\hline TLM & 1.03 & 1.25 & 2.00 & 1.03 & 1.25 \\
\hline TLC & - & 4.50 & 1.03 & - & 4.50 \\
\hline TLH & - & 0.56 & 4.13 & - & 4.50 \\
\hline TLE & 2.50 & 1.50 & 4.50 & 2.50 & 0.75 \\
\hline TFW & 1.13 & - & 2.50 & 0.56 & - \\
\hline TFM & 1.13 & - & 2.50 & 0.56 & - \\
\hline TFC & - & 0.56 & 1.03 & - & 0.84 \\
\hline TFH & - & 1.13 & 1.03 & - & 0.56 \\
\hline TFE & - & 1.13 & 1.03 & - & 0.56 \\
\hline
\end{tabular}

$\mathrm{P}=$ P. pubescens $; \mathrm{T}=$ P. triloculare $; \mathrm{L}=$ leaf; $\mathrm{F}=$ fruit; $\mathrm{W}=$ water $; \mathrm{M}=$ methanol; $\mathrm{C}=$ chloroform; $\mathrm{H}=$ hexane; $\mathrm{E}=$ ethyl acetate - indicates that the $\Sigma$ FIC could not be determined.

Synergy $($ bold text $)=\leq 0.5$; Additive (italics) $=>0.5-1.0$; Indifferent (no highlighting $)=>1.0-\leq 4 ;$ Antagonistic $($ underlined text $)=>4.0$

Numbers indicate the mean FIC values of duplicate determinations

should be avoided as chemotherapeutic options against $K$. pneumoniae infections.

\section{Combinational effects on bacterial triggers of multiple sclerosis ( $A$. baylyi and $P$. aeruginosa)}

A range of interactions were observed between Petalostigma spp. extracts and conventional antibiotics against A. baylyi (Table 5). Four of the combinations were antagonistic. Three of these antagonistic combinations involved combinations of gentamicin with either with $P$. pubescens leaf water and ethyl acetate extracts or with aqueous $P$. triloculare leaf extract. The combination of the P. pubescens leaf ethyl acetate extract with erythromycin was also determined to be antagonistic. Thus, these combinations should be avoided for the treatment of A. baylyi infections. Of the other combinations, approximately $23 \%$ were additive and nearly half of those were in combination with tetracycline. Thus, these combinations may be beneficial due to increased growth inhibitory efficacies. Of greater interest, a total of seven synergistic combinations were observed. Interestingly, 
Table 5: $\Sigma$ FIC values of Petalostigma spp. extracts in combination with conventional antibiotics against A. baylyi (ATCC 33304).

\begin{tabular}{|c|c|c|c|c|c|}
\hline & 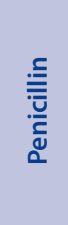 & 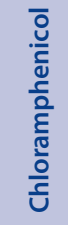 & 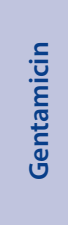 & 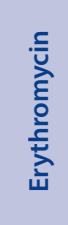 & 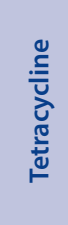 \\
\hline PLW & 1.13 & 1.50 & 5.00 & 1.50 & 0.50 \\
\hline PLM & 1.06 & 1.25 & 3.00 & 1.25 & 0.38 \\
\hline PLC & - & 2.50 & 1.03 & 2.50 & 1.13 \\
\hline PLH & - & 2.50 & 1.03 & 0.63 & 1.13 \\
\hline PLE & 2.50 & - & 4.50 & 4.00 & 0.38 \\
\hline PFW & 1.06 & 1.25 & 3.00 & 1.25 & 0.38 \\
\hline PFM & 1.03 & 1.13 & 2.00 & 1.13 & 0.63 \\
\hline PFC & - & 2.50 & 0.52 & 2.50 & 1.13 \\
\hline PFH & - & 2.50 & 1.03 & 0.63 & 0.56 \\
\hline PFE & - & 0.63 & 1.03 & 2.50 & 0.56 \\
\hline TLW & 1.13 & 0.75 & 5.00 & 1.50 & 0.50 \\
\hline TLM & 0.53 & 0.63 & 1.50 & 0.63 & 0.75 \\
\hline TLC & - & 2.50 & 1.03 & 2.50 & 0.56 \\
\hline TLH & - & 2.50 & 2.06 & 2.50 & 0.56 \\
\hline TLE & - & 0.63 & 2.06 & 2.50 & 0.28 \\
\hline TFW & 0.56 & 0.75 & 2.50 & 0.75 & 0.50 \\
\hline TFM & 1.06 & 1.25 & 3.00 & 1.25 & 0.75 \\
\hline TFC & - & 2.50 & 1.03 & 0.63 & 0.56 \\
\hline TFH & - & 2.50 & 1.03 & 2.50 & 0.84 \\
\hline TFE & - & 2.50 & 1.03 & 2.50 & 0.56 \\
\hline
\end{tabular}

$\mathrm{P}=$ P. pubescens $; \mathrm{T}=$ P. triloculare $; \mathrm{L}=$ leaf $; \mathrm{F}=$ fruit $; \mathrm{W}=$ water $; \mathrm{M}=$ methanol; $\mathrm{C}=$ chloroform; $\mathrm{H}=$ hexane; $\mathrm{E}=$ ethyl acetate - indicates that the $\Sigma$ FIC could not be determined.

Synergy $($ bold text $)=\leq 0.5$; Additive $($ italics $)=>0.5-1.0$; Indifferent $($ no high lighting $)=>1.0-\leq 4$; Antagonistic $($ underlined text $)=>4.0$

Numbers indicate the mean FIC values of 4 determinations

all synergistic interactions occurred when extracts were combined with tetracycline against $A$. baylyi. As a general trend, the higher polarity (water and methanol) to mid-polarity (ethyl acetate) extracts interacted synergistically with tetracycline. These include aqueous $(\Sigma$ FIC $=0.5)$, methanolic $(\Sigma$ FIC $=0.38)$ and ethyl acetate $(\Sigma$ FIC $=0.38)$ P. pubescens leaf extracts; the aqueous $P$. pubescens fruit extract $(\Sigma$ FIC $=0.38)$; the aqueous $(\Sigma \mathrm{FIC}=0.5)$ and ethyl acetate $(\Sigma \mathrm{FIC}=0.28)$ P. triloculare leaf extracts; and the aqueous $P$. triloculare fruit extract $(\Sigma$ FIC $=0.5)$.

Table 6 summarises the interactions of Petalostigma spp. extracts and conventional antibiotics against $P$. aeruginosa. Several extracts interacted additively with all of the conventional antibiotics tested, producing a total of seven additive combinations. In contrast, the $P$. pubescens leaf ethyl acetate extract and the $P$. triloculare leaf ethyl acetate extract were antagonistic when combined with gentamicin. A further general trend from these studies indicated that most antagonistic results occurred when gentamicin was used in combination with Petalostigma spp. leaf extracts, with some notable exceptions. Thus, the combination of gentamycin and any Petalostigma spp. leaf extract should be avoided.
Table 6: $\Sigma$ FIC values of Petalostigma spp. extracts in combination with conventional antibiotics against $P$. aeruginosa (ATCC 33304).

\begin{tabular}{|c|c|c|c|c|c|}
\hline & 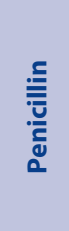 & 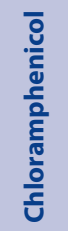 & 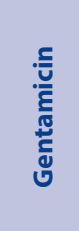 & 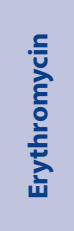 & 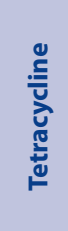 \\
\hline PLW & 1.13 & 1.13 & 3.00 & 1.13 & 0.56 \\
\hline PLM & 1.13 & 1.06 & 2.00 & 1.06 & 1.06 \\
\hline PLC & 1.00 & 1.00 & 1.06 & - & - \\
\hline PLH & 0.63 & 1.00 & 1.06 & - & - \\
\hline PLE & 1.56 & 2.50 & 10.00 & 2.50 & 0.63 \\
\hline PFW & 1.06 & 1.06 & 2.00 & 1.06 & 1.06 \\
\hline PFM & 1.03 & 1.03 & 3.00 & 1.03 & 1.03 \\
\hline PFC & - & - & 0.53 & - & - \\
\hline PFH & - & - & 1.06 & - & - \\
\hline PFE & - & - & 1.06 & - & - \\
\hline TLW & 0.63 & 0.63 & 2.50 & 0.62 & 1.13 \\
\hline TLM & 1.06 & 1.06 & 2.00 & 1.06 & 1.03 \\
\hline TLC & - & - & 1.06 & - & - \\
\hline TLH & - & - & 1.06 & - & - \\
\hline TLE & - & - & 8.50 & - & - \\
\hline TFW & 1.06 & 1.06 & 2.00 & 1.06 & 1.06 \\
\hline TFM & 1.03 & 1.03 & 1.50 & 1.03 & 1.03 \\
\hline TFC & - & - & 2.13 & - & - \\
\hline TFH & - & - & 2.50 & - & - \\
\hline TFE & - & - & 2.50 & - & - \\
\hline
\end{tabular}

$\mathrm{P}=$ P. pubescens $; \mathrm{T}=$ P. triloculare $; \mathrm{L}=$ leaf $; \mathrm{F}=$ fruit $; \mathrm{W}=$ water $; \mathrm{M}=$ methanol; $\mathrm{C}=$ chloroform $; \mathrm{H}=$ hexane; $\mathrm{E}=$ ethyl acetate - indicates that the $\Sigma$ FIC could not be determined.

Synergy $($ bold text $)=\leq 0.5$; Additive $($ italics $)=>0.5-1.0$; Indifferent $($ no high lighting $)=>1.0-\leq 4 ;$ Antagonistic $($ underlined text $)=>4.0$

Numbers indicate the mean FIC values of duplicate determinations.

\section{Combinational effects on a bacterial trigger of rheumatic fever (S. pyogenes)}

The interactive antimicrobial interactions of Petalostigma spp. extracts with various conventional antibiotics against $S$. pyogenes are summarised in Table 7. A total of 12 combinations were categorised as being additive interactions and thus may be beneficial in treating $S$. pyogenes infections. However, the $P$. triloculare fruit hexane extract was antagonistic in combination with tetracycline and thus this combination should be avoided as a chemotherapeutic option to treat $S$. pyogenes infections. This was the only antagonistic result determined against $S$. pyogenes, indicating that all other combinations will not counter-indicate with the inhibitory properties of the conventional antibiotics and instead may have limited beneficial effects.

\section{Varied ratio combination studies (isobolograms) Synergistic interactions with penicillin-G}

Three combinations of Petalostigma spp. extract with penicillin-G were identified as inducing synergistic interactions (Figure 6). Notably, all of 
Table 7: $\Sigma$ FIC values of Petalostigma spp. extracts in combination with conventional antibiotics against $S$. pyogenes.

\begin{tabular}{|c|c|c|c|c|c|}
\hline & $\frac{. \subseteq}{\overline{\bar{E}}}$ & 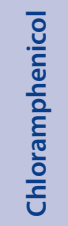 & 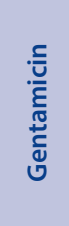 & 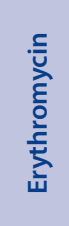 & 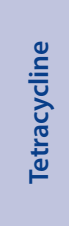 \\
\hline PLW & 1.06 & 1.06 & 2.00 & 1.06 & 1.25 \\
\hline PLM & 1.02 & 1.02 & 1.25 & 1.02 & 1.06 \\
\hline PLC & 2.50 & 2.50 & 1.25 & 2.50 & - \\
\hline PLH & - & - & 1.06 & - & 2.50 \\
\hline PLE & 1.13 & 1.13 & 3.00 & 1.13 & 0.75 \\
\hline PFW & 0.53 & 0.53 & - & 0.53 & 0.63 \\
\hline PFM & 1.01 & 1.01 & 1.13 & 1.01 & 1.03 \\
\hline PFC & - & - & 1.06 & - & 2.50 \\
\hline PFH & - & - & 2.13 & - & 0.62 \\
\hline PFE & 1.13 & 1.13 & 3.00 & 1.13 & 0.75 \\
\hline TLW & 1.02 & 1.02 & 1.25 & 1.01 & 1.06 \\
\hline TLM & 1.01 & 1.01 & 1.13 & 1.01 & 1.03 \\
\hline TLC & - & - & 0.53 & - & 2.50 \\
\hline TLH & 2.50 & 0.63 & 1.25 & 2.50 & - \\
\hline TLE & 1.06 & 1.06 & 2.00 & 1.06 & 1.25 \\
\hline TFW & 1.03 & 1.03 & 1.50 & 1.03 & 1.13 \\
\hline TFM & 1.03 & 1.03 & 1.50 & 1.03 & 1.13 \\
\hline TFC & - & - & 1.06 & - & 2.50 \\
\hline TFH & 2.50 & 2.50 & 1.25 & 2.50 & 4.00 \\
\hline TFE & 0.63 & 0.63 & 2.50 & 0.63 & - \\
\hline
\end{tabular}

$\mathrm{P}=$ P. pubescens $; \mathrm{T}=$ P. triloculare $\mathrm{L}=$ leaf $\mathrm{F}=$ fruit $\mathrm{W}=$ water $\mathrm{M}=$ methanol; $\mathrm{C}=$ chloroform; $\mathrm{H}=$ hexane; $\mathrm{E}=$ ethyl acetate - indicates that the $\Sigma \mathrm{FIC}$ could not be determined.

Synergy $($ bold text $)=\leq 0.5$; Additive (italics) $=>0.5-1.0$; Indifferent (no highlighting $)=>1.0-\leq 4 ;$ Antagonistic $($ underlined text $)=>4.0$

Numbers indicate the mean FIC values of duplicate determinations

these synergistic combinations occurred when tested against $P$. mirabilis growth. These combinations were further examined using isobologram analysis across a range of extract: penicillin-G ratios to identify the ideal ratios to obtain synergy. Interestingly, all of the ratios of $P$. pubescens fruit hexane extract and penicillin-G worked synergistically as $P$. mirabilis growth inhibitors (Figure 6a). Similarly, all combination ratios of the P. pubescens fruit ethyl acetate extract and penicillin-G produced synergistic interactions (Figure $6 \mathrm{~b}$ ). Thus, all ratios of these combinations would be beneficial to enhance $P$. mirabilis growth inhibition. However, bacteria would be less likely to develop resistance when combinations are used in ratios which minimise the amount of conventional antibiotic used. Thus, for long term prophylactic treatment (as would be required to prevent and treat rheumatoid arthritis), the ideal extract: penicillin-G ratio may be 90:10. However, when used for the treatment of acute infections (e.g. urinary tract infections), the ratio which maximises the efficacy of the treatment (i.e. the 10:90 ratio) may be the preferred option.
Table 8: $\mathrm{LC}_{50}$ values determined for Petalostigma spp. fruit and leaf extracts in the Artemia nauplii and HDF bioassays following $24 \mathrm{~h}$ exposure.

\begin{tabular}{|c|c|c|c|c|}
\hline \multirow[t]{2}{*}{ Species } & & $\begin{array}{c}\text { Extract } \\
\text { ALA }\end{array}$ & \multicolumn{2}{|c|}{$\mathrm{LC}_{50}$ value $(\mu \mathrm{g} / \mathrm{mL})$} \\
\hline & \multirow{5}{*}{ 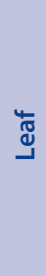 } & Water & 661 & - \\
\hline \multirow{8}{*}{ 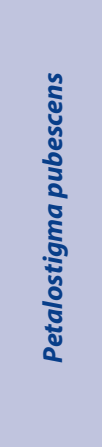 } & & Methanol & 749 & - \\
\hline & & Chloroform & - & - \\
\hline & & Hexane & - & - \\
\hline & & Ethyl Acetate & 750 & - \\
\hline & \multirow{5}{*}{ 莺 } & Water & 733 & - \\
\hline & & Methanol & 735 & - \\
\hline & & Chloroform & - & - \\
\hline & & Hexane & - & - \\
\hline \multirow{11}{*}{ 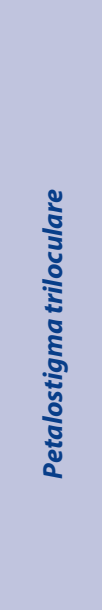 } & & Ethyl Acetate & 750 & - \\
\hline & \multirow{5}{*}{ ๘ } & Water & 750 & - \\
\hline & & Methanol & 1135 & - \\
\hline & & Chloroform & - & - \\
\hline & & Hexane & - & - \\
\hline & & Ethyl Acetate & 1505 & - \\
\hline & \multirow{5}{*}{ 売 } & Water & 750 & - \\
\hline & & Methanol & 750 & - \\
\hline & & Chloroform & - & - \\
\hline & & Hexane & - & - \\
\hline & & Ethyl Acetate & 750 & - \\
\hline
\end{tabular}

- indicates that less than $50 \%$ mortality was induced by the extract at all concentrations tested.

$100 \%$ mortality was induced by potassium dichromate (positive control) and none by the sea water (negative control) at $1000 \mu \mathrm{g} / \mathrm{mL}$.

In contrast, the $P$. triloculare leaf ethyl acetate extract in combination with penicillin-G (Figure 6c) had a wider range of results. Only the ratios between $10-40 \%$ P. triloculare leaf ethyl acetate extract and $60-90 \%$ penicillin-G produced synergistic interactions. In addition, five out of the nine different ratios produced additive interactions. However, whilst 20:80, 30:70 and 40:60 extract: antibiotic ratios are classified as synergistic interactions, they were on the cut off between synergy and additive interactions. Therefore, $10 \%$ of $P$. triloculare leaf (ethyl acetate) extract and $90 \%$ penicillin-G (10:90) was deemed to be the best combination ratio for synergistic $P$. mirabilis growth inhibition.

\section{Synergistic interactions with chloramphenicol}

Three combinations of Petalostigma spp. extract with chloramphenicol induced synergistic interactions for P. mirabilis growth inhibition (Figure 7). Interestingly, all ratios of $P$. pubescens fruit hexane extract and chloramphenicol produced synergistic inhibition against $P$. mirabilis growth (Figure 7a). Similarly, all ratios of the $P$. triloculare leaf hexane extract and 


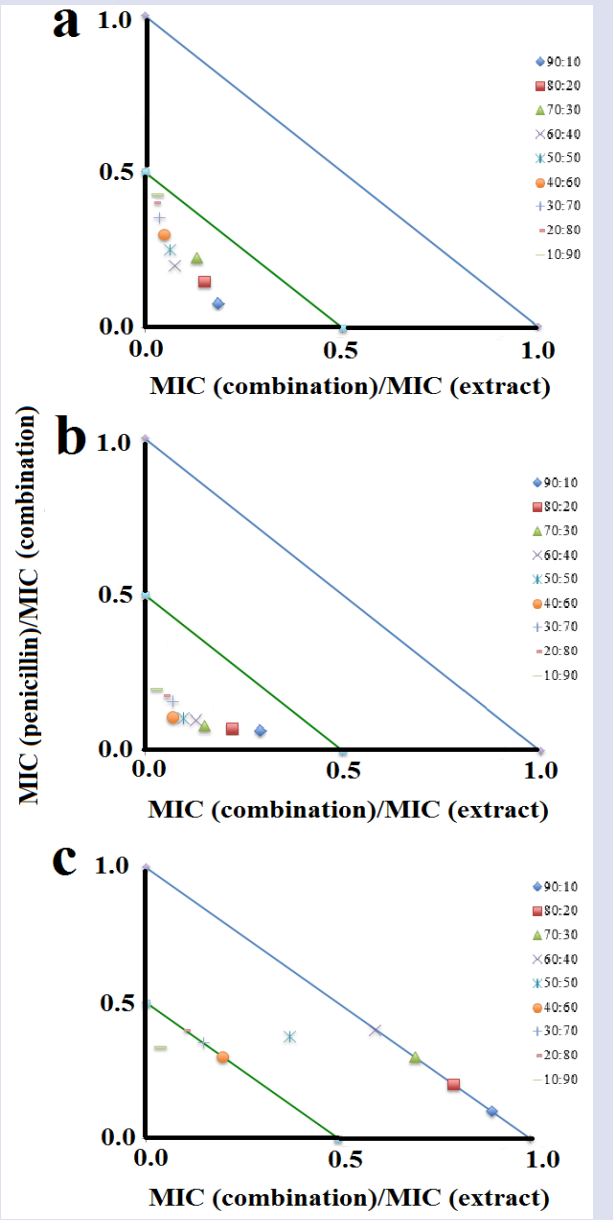

Figure 6: Isobologram for combinations of penicillin-G and (a) $P$. pubescens fruit hexane extract, (b) P. pubescens fruit ethyl acetate extract, (c) P. triloculare leaf ethyl acetate extract tested at various ratios against $P$. mirabilis (ATCC: 21721). Results represent mean MIC values of four replicates. Ratio $=\%$ extract: $\%$ antibiotic. Ratios lying on or underneath the green line are considered to be synergistic ( $\Sigma$ FIC $\leq$ $0.5)$. Any points between the green and blue line or on the blue line are deemed additive $(\Sigma \mathrm{FIC}>0.5-1.0)$.

chloramphenicol produced synergistic growth inhibition of $P$. mirabilis (Figure $7 \mathrm{~b}$ ). Therefore all ratios would be beneficial treatment options to enhance $P$. mirabilis growth inhibition. However, for long term prophylactic treatment, $90 \%$ extract and $10 \%$ chloramphenicol may be the ideal ratio for long term usage, whilst the 10:90 ratio may be preferential for the treatment of acute infections.

The combination of $P$. triloculare leaf ethyl acetate extract and chloramphenicol produced a wide range of results (Figure 7c). Four additive ratios were detected. Furthermore, combinations of 20-50\% extract and 50-80\% antibiotic acted synergistically against $P$. mirabilis growth. The ideal synergistic ratio for the treatment and prevention of rheumatoid arthritis (i.e. the treatment that minimises the amount of chloramphenicol used) was identified to be $50 \%$ P. triloculare leaf ethyl acetate extract and $50 \%$ chloramphenicol. In contrast, the preferred ratio for acute infections (the highest antibiotic \% to maximise the efficacy of the treatment) is the $20 \%$ P. triloculare leaf ethyl acetate extract and $80 \%$ chloramphenicol ratio.

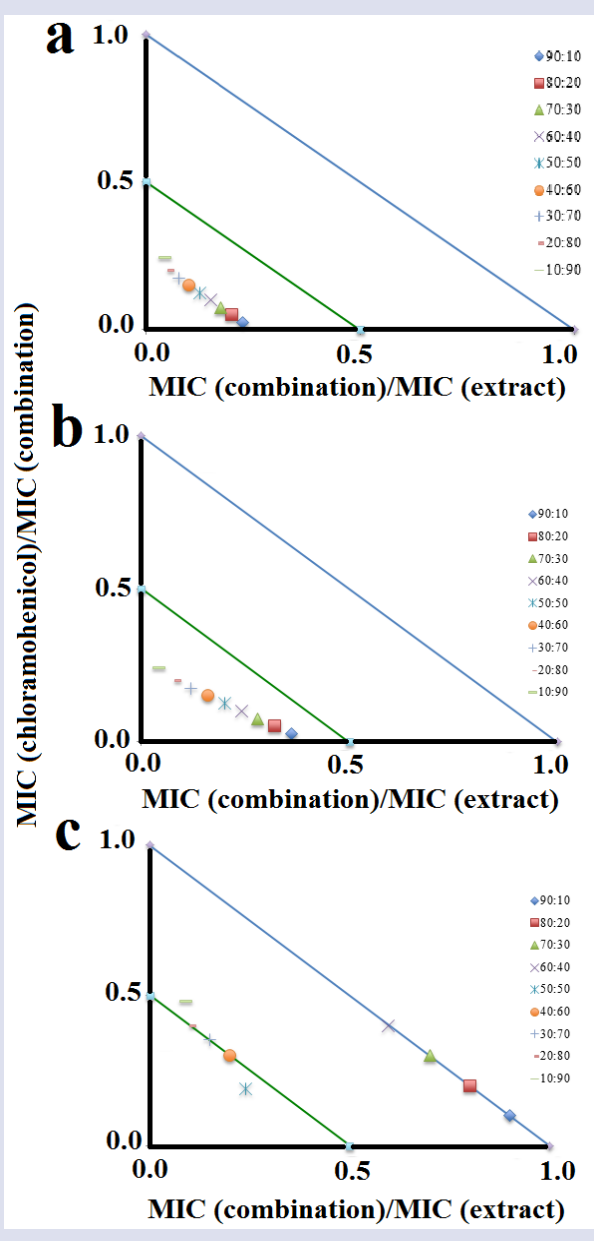

Figure 7: Isobologram for combinations of chloramphenicol and (a) $P$. pubescens fruit hexane extract, (b) P. triloculare leaf hexane extract, (c) $P$. triloculare leaf ethyl acetate extract tested at various ratios against P. mirabilis (ATCC: 21721). Results represent mean MIC values of four replicates. Ratio $=\%$ extract: $\%$ antibiotic. Ratios lying on or underneath the green line are considered to be synergistic $(\Sigma$ FIC $\leq 0.5)$. Any points between the green and blue line or on the blue line are deemed additive ( $\Sigma \mathrm{FIC}>0.5-1.0)$.

\section{Synergistic interactions with erythromycin}

The antimicrobial interactions between the P. pubescens fruit hexane extract and erythromycin (Figure 8) follows a similar trend to that observed for the combination of the Petalostigma extracts with either penicillin-G or chloramphenicol. Nearly all of the combinations of extract: antibiotic were synergistic. The 10:90 and 20:80 ratios produced additive interactions. All other ratios were synergistic inhibitors of P. mirabilis growth. The ideal synergistic ratio for growth inhibition of P. mirabilis in the treatment and prevention of rheumatoid arthritis is the 90\% P. pubescens fruit (hexane) extract:10\% erythromycin ratio, whilst the 30:70 ratio may be preferred for the treatment of acute infections.

\section{Synergistic interactions with tetracycline}

Seven different combinations of Petalostigma spp. extract and tetracycline were identified as synergistic against the growth of $A$. baylyi. Of these, four combinations contained P. pubescens extracts (Figure 9) and three combinations contained $P$. triloculare extracts (Figure 10). Therefore, 


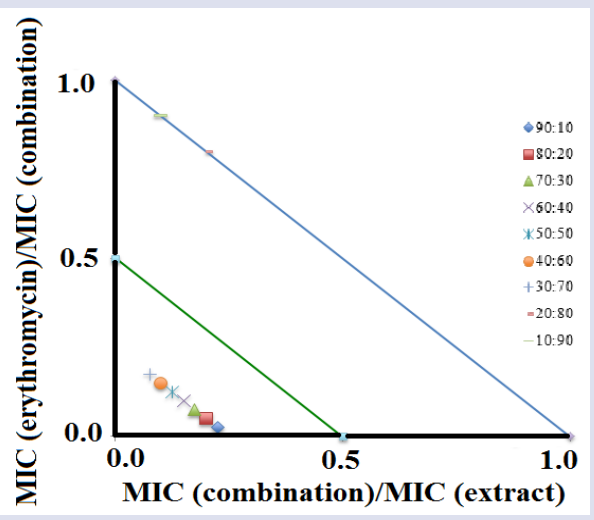

Figure 8: Isobologram for combinations of erythromycin and $P$. pubescens fruit hexane extract tested at various ratios against P. mirabilis (ATCC: 21721). Results represent mean MIC values of four replicates. Ratio $=\%$ extract: \% antibiotic. Ratios lying on or underneath the green line are considered to be synergistic ( $\Sigma$ FIC $\leq 0.5)$. Any points between the green and blue line or on the blue line are deemed additive $(\Sigma$ FIC $>0.5-1.0)$.

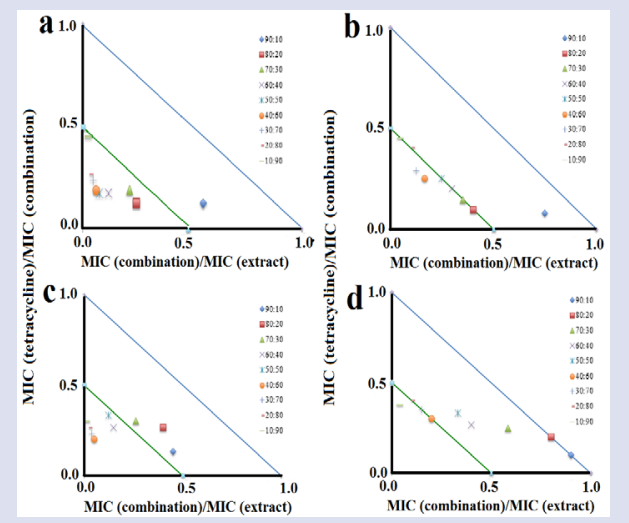

Figure 9: Isobologram for combinations of tetracycline and $P$. pubescens extracts tested at various ratios against $A$. baylyi (ATCC: 33304): (a) aqueous leaf extract, (b) methanolic leaf extract, (c) leaf ethyl acetate extract, (d) aqueous fruit extract. Results represent mean MIC values of four replicates. Ratio $=\%$ extract: $\%$ antibiotic. Ratios lying on or underneath the green line are considered to be synergistic $(\Sigma \mathrm{FIC} \leq 0.5)$. Any points between the green and blue line or on the blue line are deemed additive ( $\Sigma \mathrm{FIC}>0.5-1.0)$.

various different ratios of these combinations were tested in order to identify the ideal ratio to obtain synergy. Nearly all of the ratios of $P$. pubescens leaf water extract with tetracycline acted synergistically against the growth of $A$. baylyi (Figure 9a). The $90 \%$ extract:10\% tetracycline ratio was the only exception to this trend. The ideal synergistic ratio for growth inhibition of $A$. baylyi in the treatment and prevention of multiple sclerosis is $80 \%$ extract and $20 \%$ tetracycline, whilst the $10: 90$ ratio may be preferred for the treatment of acute $A$. baylyi infections. Similarly, the $P$. pubescens methanolic leaf extract was also determined to interact synergistically in combination with tetracycline at nearly all ratios. Indeed, only the $90 \%$ extract, $10 \%$ tetracycline combination was non-synergistic. Instead, this combination produced an additive interaction (Figure 9b). Thus, the ideal combination ratios are the same as for the $P$. pubescens leaf water extract: tetracycline combination.

The ratios of $P$. pubescens leaf ethyl acetate extract in conjunction with tetracycline which interact synergistically were also determined (Figure 9c). Ratios between $10-60 \%$ extract and $40-90 \%$ antibiotic produced synergistic interactions. The $60 \%$ P. pubescens leaf ethyl acetate extract and $40 \%$ of tetracycline combination was determined to be the best ratio for synergistically inhibiting the growth of A. baylyi for longer term therapy whilst a $10 \%$ extract, $90 \%$ tetracycline ratio may be preferred for the treatment of acute A. baylyi infections. Similarly, the P. pubescens fruit water extract also interacted synergistically in combination with tetracycline in some ratios, yet additively against $A$. baylyi growth in other ratios. Ratios between $10-40 \%$ extract and $60-90 \%$ antibiotic were determined to produce synergistic interactions (Figure 9d). The preferred ratio to produce a synergistic interaction to inhibit the growth of baylyi in the treatment and prevention of multiple sclerosis is $10 \%$ of P. pubescens fruit water extract in combination with $90 \%$ of tetracycline. The $10 \%$ extract, $90 \%$ tetracycline ratio is preferred for the treatment of acute A. baylyi infections.

Figure 10a represents the interaction between $P$. triloculare leaf water extract in combination with tetracycline against $A$. baylyi growth. With a few notable exceptions (90:10 and 80:20, extract: tetracycline ratios), the majority of the extract: antibiotic combination ratios interacted synergistically for inhibiting the growth of $A$. baylyi. Similarly, all combinations of $P$. triloculare leaf ethyl acetate extract with tetracycline interacted synergistically for A. baylyi growth inhibition except the 90:10 and 80:20, extract: tetracycline ratios (Figure 10b). Thus 70\% P. pubescens fruit water extract with $30 \%$ of tetracycline was deemed the preferred combination ratio to produce a synergistic interaction to inhibit the growth of baylyi in the treatment and prevention of multiple sclerosis. The $10 \%$ extract, $90 \%$ tetracycline ratio is preferred for the treatment of acute A. baylyi infections. In contrast, combinations of $\leq 50 \%$ P. triloculare fruit water extract and $\geq 50 \%$ of tetracycline produced synergistic interactions for $A$. baylyi growth inhibition (Figure 10c). The best ratio for long term inhibition of $A$. baylyi growth was determined to be a mixture of $50 \%$ P. triloculare (fruit-water) extract with $50 \%$ tetracycline, whereas $10 \%$ extract with $90 \%$ tetracycline was deemed the best ratio for acute $A$. baylyi infections.

\section{Quantification of toxicity}

No $\mathrm{LC}_{50}$ values were determined for the chloroform and hexane extracts of either species as $<50 \%$ mortality was seen in all tested concentrations (Table 8). As extracts with $\mathrm{LC}_{50}$ values $<1000 \mu \mathrm{g} / \mathrm{ml}$ towards Artemia nauplii have previously been defined as being toxic in this assay, ${ }^{15,16}$ all chloroform and hexane extracts were deemed to be nontoxic. With the exception of aqueous and ethyl acetate extracts of $P$. triloculare leaf, all other Petalostigma spp. extracts were considered to be moderately toxic. Although the A. franciscana nauplii lethality assay is generally quite robust, it is noteworthy that brine shrimp are quite sensitive to changes in $\mathrm{pH} .{ }^{17}$ Acidic $\mathrm{pH}$ can suppress the rate of mitochondrial protein synthesis and potentially be fatal to the growth and development of nauplii. The presence of phenolic acids in the high-mid polarity extracts could potentially provide falsely high toxicity estimations. Indeed, previous studies have reported that extracts high in ascorbic acid can provide fallacious toxicity determinations. ${ }^{18}$ Thus, this assay may have overestimated the toxicity of these extracts. In contrast, all plant extracts and conventional antibiotics demonstrated a lack of toxicity towards normal human primary dermal fibroblasts, with cellular viability for all tests substantially 


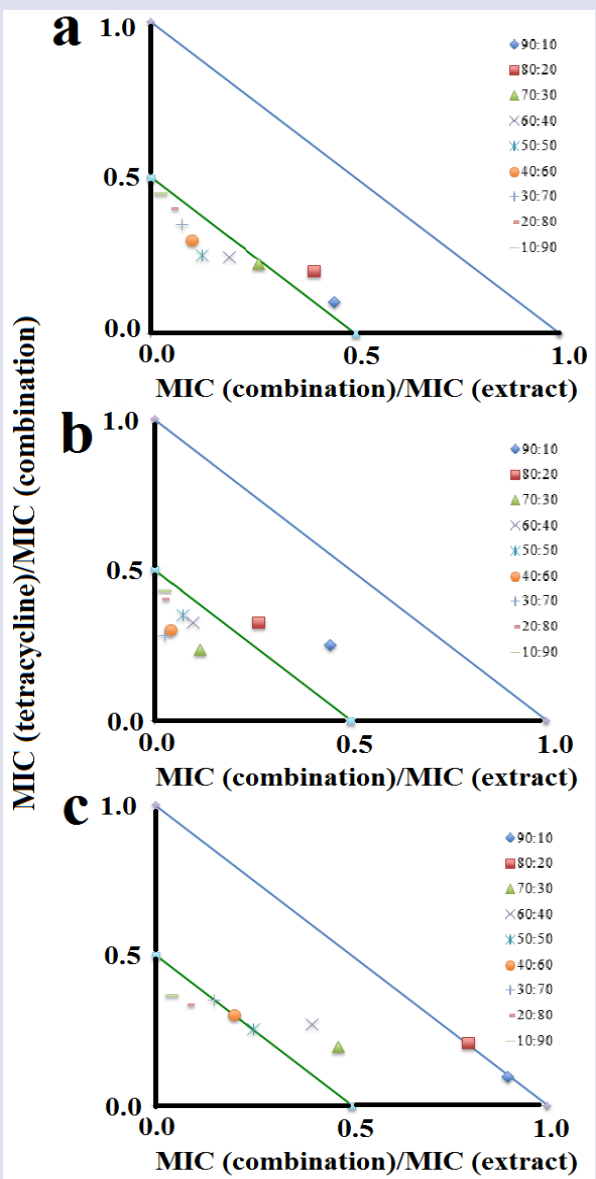

Figure 10: Isobologram for combinations of tetracycline and $P$. triloculare extracts tested at various ratios against A. baylyi (ATCC: 33304): (a) aqueous leaf fruit extract, (b) leaf ethyl acetate extract, (c) aqueous fruit extract. Results represent mean MIC values of four replicates. Ratio $=\%$ extract: $\%$ antibiotic. Ratios lying on or underneath the green line are considered to be synergistic $(\Sigma \mathrm{FIC} \leq 0.5)$. Any points between the green and blue line or on the blue line are deemed additive $(\Sigma \mathrm{FIC}$ $>0.5-1.0)$.

$>50 \%$ of the untreated control. All extracts were therefore deemed to be either nontoxic or of only low-moderate toxicity.

\section{DISCUSSION}

This study investigated the ability of Petalostigma spp. to inhibit the growth of some bacterial triggers of autoimmune inflammatory diseases, both alone and in combination with conventional antibiotics. Several Petalostigma spp. extracts were identified as effective bacterial growth inhibitors. In particular, the aqueous and methanolic extracts were strong inhibitors of K. pneumoniae and S. pyogenes growth, with MIC values with MICs as low as $344 \mu \mathrm{g} / \mathrm{mL}$. However, the MIC values of most of the Petalostigma spp. extracts was substantially above $1000 \mu \mathrm{g} / \mathrm{mL}$ and are thus indicative of only low to moderate inhibitory activity. Whilst a detailed investigation of the phytochemistry of the Petalostigma spp. extracts was beyond the scope of this study, the qualitative phytochemical studies highlighted several phytochemical classes that may contribute to the bacterial growth inhibitory activity. Interestingly, nearly all of the water and methanolic extracts of Petalostigma spp. had relatively high abundances in flavonoids, tannins, phenols, triterpenoids and free anthraquinones. Many studies have reported potent antibacterial activities for a wide variety of flavonoids. ${ }^{19}$ This has been attributed to a variety of mechanisms, including their ability to complex with extracellular and soluble proteins and as well as bacterial cell walls. ${ }^{20}$ Similarly, multiple tannins have broad spectrum antibacterial activity via a variety of intra and extracellular mechanisms, including the precipitation of microbial proteins. ${ }^{21}$ Phenolics are toxic to microorganisms via enzyme inhibition mechanisms, possibly through non-specific interaction with proteins or by reaction with sulfhydryl groups. ${ }^{22}$ Quinones can complex irreversibly with nucleophilic amino acids in proteins, generally leading to inactivation of the protein and loss of function, thus triggering microbial death. ${ }^{22}$ Triterpenoids also have antibacterial activity, although the inhibitory mechanism is yet to be identified..$^{23}$ It is likely that other phytochemical classes may also contribute to the growth inhibitory properties of these extracts. Therefore, phytochemical evaluation studies and bioactivity driven isolation of active components are required to evaluate the mechanism of Petalostigma spp. growth inhibition.

The combinational studies with conventional antibiotics were of greater interest. Several combinations displayed substantially greater potential as therapeutic agents against bacterial triggers of rheumatoid arthritis and multiple sclerosis than the extracts or antibiotics did alone. A total of 14 synergistic combinations were identified in this study with seven synergistic combinations each noted against both $P$. mirabilis and A. baylyi. The implications of a synergistic interaction include enhanced efficacy, thereby allowing lower dose administration, with reduced side effects and possibly reduced antimicrobial resistance or conversely greater efficacy with administration of the same dosage. ${ }^{15}$ Seven combinations of plant extracts had synergistic activity with penicillin-G, chloramphenicol and erythromycin against the growth of $P$. mirabilis. Notably, $P$. mirabilis was initially completely non-susceptible to chloramphenicol, erythromycin and half of the extracts that proved to be synergistic in the combinational studies. Thus, this study identified combinations of plant extracts and antibiotics which may repurpose relatively ineffective antibiotics and greatly enhance their efficacy, even against otherwise resistant bacterial strains. All of the extracts in synergistic combinations against $P$. mirabilis were mid-low polarity (hexane or ethyl acetate) suggesting the presence of a common active compound or class of compounds that may be responsible for the synergistic effects. Furthermore, several of these hexane extracts induced synergy at nearly all ratios of extract:antibiotic. This is surprising as previous studies with other plant species generally report that different ratios tend to provide a mix of interactions, generally with additive, indifferent and a few synergistic interactions. ${ }^{15}$ However, the isobolograms of $P$. pubescens fruit-hexane and $P$. triloculare leaf-hexane uniformly produced synergistic interactions despite the antibiotic tested. Furthermore, most of the hexane extracts were synergistic with antibiotics at concentrations as low as $10 \%$, further emphasising the efficacy of the extracts. Such a trend is consistent with irreversible mechanisms such as clavulanic acid/ $\beta$-lactam antibiotic combinations ${ }^{23}$ and future studies will aim at testing the synergistic mechanism and whether it is due to irreversible events. In contrast, other synergistic extract: antibiotic combinations produced a wider range of interactions, including synergistic, additive and indifferent interactions. This is more consistent with reversible competition between the extract component(s) and the conventional antibiotic for binding to an effector. ${ }^{24}$

Microbes have developed numerous resistance mechanisms to avoid the effects of antibiotics. One main method is through the use of multi-drug resistant (MDR) efflux pumps which are encoded chromosomally and utilised to rapidly remove antibiotics that have entered the bacterial cells, thus rendering them resistant to the effects of the antibiotic. ${ }^{25,26} \mathrm{~A}$ single 
pump may allow the bacteria to escape several types of antimicrobials. When these efflux pumps are inhibited, the intracellular concentration of antibiotic will increase, allowing the treatment to once again be effective. Interestingly, many plants possess MDR pump inhibitors in order to enhance the activity of their own natural antimicrobial compounds. Such MDR pump inhibitors become great tools when used in combination with some previously ineffective/resistance prone antibiotic compounds and several examples have previously been reported. ${ }^{26}$ Isoflavones isolated from Lupinus argenteus potentiate the activity of the natural plant antibiotic berberine as well as the synthetic fluoroquinoline antibiotic, norfloxacin as inhibitors of $S$. aureus growth. ${ }^{26}$ That study reported that the isoflavone allows a greater concentration of berberine in the bacteria by inhibiting the efflux mechanism (MDR pump). Similarly, Mezoneuron benthamianum and Securinega virosa extracts act as efflux pump inhibitors for fluoroquinolone, tetracycline and erythromycin in resistant strains of S. aureus (MRSA). ${ }^{27}$ As a consequence, the M. benthamianum ethanol extract and chloroform extract of $S$. virosa reduce the MIC (minimum inhibitory concentration) of norfloxacin against $S$. aureus by a factor of 4 . In our study, $P$. mirabilis was completely non-susceptible to chloramphenicol, tetracycline and erythromycin, with only a low susceptibility to penicillin. All of these antibiotics are susceptible to resistance due to efflux pumps. ${ }^{3,28}$ A single pump can provide bacteria with resistance to a wide array of chemically and structurally diverse antibiotics and it is not uncommon for an organism to code for more than one efflux pump. ${ }^{3,28}$ It is therefore imperative to identify agents that can block the efflux mechanism (efflux pump inhibitors - EPIs) or alter the process of efflux and in so doing, extend the life of existing antibacterial drugs. Plants produce various secondary metabolites that are used as defense mechanisms against pathogenic invaders. Some plants produce antimicrobials which, along with other compounds, inhibit the efflux of those antimicrobials from a bacterial cell. There are currently no EPI/antimicrobial drug combinations on the market, although research into identifying potential EPIs is ongoing. ${ }^{28}$ The synergistic interaction against $P$. mirabilis in our study suggests the possibility of a common EPI in the P. pubescens fruit (hexane and ethyl acetate) and $P$. triloculare (hexane and ethyl acetate) extracts that could be inhibiting a MDR efflux pump in the microbe.

Alternatively (or in addition to MDR efflux pumps), the P. mirabilis strain used in our study may have acquired genes encoding for reduced-affinity penicillin-binding protein 2a (PBP2a) (rendering $\beta$-lactam antibiotics ineffective). ${ }^{29}$ It is likely that as penicillin binding proteins are a group of protein enzymes, these phytochemicals may form nonspecific interaction and affect the bacterial cell biosynthesis. The P. pubescens fruit and $P$. triloculare leaf hexane extracts may also contain a $\beta$-lactamase inhibitor. $\beta$-lactamases are the major defense of gram-negative bacteria against $\beta$-lactam antibiotics. ${ }^{30}$ Clavulanic acid is an irreversible $\beta$-lactamase inhibitor, which in combination with $\beta$-lactam antibiotics can block the bacterial antimicrobial resistance mechanism. The Petalostigma spp. hexane extracts- $\beta$-lactam antibiotic combinations have inhibitory profiles similar with those of clavulanic acid- $\beta$-lactam combinations. ${ }^{24}$ Neither clavulanic acid ${ }^{24}$ nor the Petalostigma spp. hexane extracts had appreciable intrinsic antimicrobial activity when tested on their own. The Petalostigma spp. hexane extracts were consistently synergistic against $P$. mirabilis growth, even at low levels of antibiotic, suggesting the possibility of a compound that behaves similarly to clavulanic acid (i.e. an irreversible/competitive inhibitor). Further studies are required to identify whether extract compounds mirror the chemical and biological characteristics of clavulanic acid (i.e. the presence of a $\beta$-lactam ring).

Seven Petalostigma spp. extracts were synergistic against $A$. baylyi when tested in combination with tetracycline against A. baylyi. All of these extracts were extracted using mid-high polarity solvents. It is likely that these extracts have overlapping phytochemical profile and the poten- tiator components may be common components of all of these extracts. However, the compound(s) which induce the synergistic effects may be in greater amounts in the $P$. pubescens (leaf-water) and $P$. triloculare (leaf-ethyl acetate) extracts in comparison to the other extract as they consistently produced synergistic interactions, even with low extract ratios. Efflux pumps are the main bacterial resistance mechanism which renders tetracycline inactive. ${ }^{31} \mathrm{~A}$ total of nine multidrug efflux systems have been identified in Acinetobacter spp. including Tet (A), a potent tetracycline efflux protein. ${ }^{32}$ Our studies suggest the possibility that certain EPIs may be common to all of the mid-high polarity extracts that were synergistic against $A$. baylyi in this study. In addition to potentiation activity, it is also likely that the extracts may themselves be participating in the inhibitory action against $A$. baylyi growth. In order to identify the active compound(s) that is/are inducing synergy, bioactive driven separation and identification studies and/or metabolomic profiling studies are required.

Ultimately, the preparation of combinations of Petalostigma spp. extract/ compound with conventional antibiotic will depend on the nature of the pathogen and of the disease treated. In general, combinations of antibiotic with pure Petalostigma spp. derived compounds would be preferred for acute infections as they are much less complex, easier to standardize and have lower chances of unwanted side effects. The use of crude extracts in these preparations is also effective and may still be acceptable to treat some diseases. However, when treating chronic illness or using a combinational approach to prevent illness (as would be required in preventing autoimmune inflammatory diseases), the use of a pure potentiator compound in combination with the antibiotic may not be desirable. Continuous exposure of bacteria to a pure antibiotic (or to a combination of a single antibiotic and single potentiator) is likely to induce resistance to one or both of the compounds in the bacteria. Indeed, some E.coli strains are now resistant to amoxicillin-clavulanic acid combinations. ${ }^{33}$ However, crude plant extracts often contain numerous antibacterial compounds which may affect multiple bacterial targets. Thus, using a plant extract (rather than pure plant compounds) in combination with an antibiotic is less likely to result in resistant bacteria. Indeed, we were unable to find any reports of any bacteria developing resistance to a crude plant extract. For this reason, when recommending preferred combination ratios throughout this study, we have recommended two different ratios for acute and chronic conditions. The lowest extract: highest antibiotic ratio which produced synergy has been deemed as the ideal ratio for treating acute bacterial infections, whilst we deemed the highest extract: lowest antibiotic ratio which produced synergy to be preferred for preventing and treating chronic disease

A further trend was evident in our study: most of the extract-antibiotic combinations which did not produce synergistic effects, generally did not greatly affect the efficacy of the antibiotic i.e. they appear to not counter-indicate with the antibiotics tested in this study. This is important as many users of herbal and traditional medicines self-diagnose/treat, often with multiple therapies concurrently. Thus, an understanding of drug herbal medicine interactions is important. Only $3.2 \%$ of the combinations tested produced antagonistic interactions with the conventional antibiotics against the bacteria tested. Most of the antagonistic combinations occurred when leaf extracts (mid-low polarity) were tested in conjunction with gentamycin, with a few exceptions. Therefore, it is likely that an inhibitory molecule may be common to mid-low polarity extracts. These are important findings and highlight combinations which should be avoided. Interestingly, previous studies indicate that antagonistic combinations of plant extracts with gentamicin are not uncommon. ${ }^{34}$ Therefore, caution must be exercised if using Petalostigma spp. extracts in conjunction with gentamicin, especially against $K$. pneumoniae. 


\section{CONCLUSION}

The results of this study demonstrate the potential of Petalostigma spp. extracts in inhibiting the growth of some bacterial triggers of autoimmune inflammatory diseases. The aqueous and methanolic extracts were moderate inhibitors of several microbes. However, the therapeutic potential of the Petalostigma spp. extracts was far more apparent when tested in combination with conventional antibiotics as potentiators. The mid-low polarity extracts were substantially better potentiators of conventional antibiotics in inhibiting the growth of Proteus mirabilis and Acinetobacter baylyi than the higher polarity extracts. Although the mechanisms of synergy are still unclear, studies indicate that compounds within Petalostigma spp. could potentially mimic the actions of a resistance modifying agent, thus potentiating the activity of several antibiotics that are relatively ineffective alone. Therefore, a combinational approach not only increases the effectiveness of drugs, but can potentially reduce the side effects and lessen the potential to develop drug resistant pathogens.

\section{ACKNOWLEDGEMENT}

Financial support for this work was provided by the Environmental Futures Research Institute and the School of Natural Sciences, Griffith University, Australia.

\section{CONFLICT OF INTEREST}

The authors declare no conflict of interest.

\section{ABBREVIATIONS}

DMSO: Dimethyl sulfoxide; $\mathbf{L C}_{50}$ : The concentration required to achieve $50 \%$ mortality; MIC: Minimum inhibitory concentration.

\section{REFERENCES}

1. Omer E, Elshamy AI, Nassar M, Shalom J, White A, Cock IE. Plantago squarrosa Murray extracts inhibit the growth of some bacterial triggers of autoimmune diseases: GC-MS analysis of an inhibitory extract. Inflammopharmacology. 2018;1-3. DOI: 10.1007/s10787-018-0547-0

2. Davies J, Davies D. Origins and evolution of antibiotic resistance. Microbiology and Molecular Biology Reviews. 2010;74(3):417-33.

3. Abreu AC, McBain AJ, Simoes M. Plants as sources of new antimicrobials and resistance-modifying agents. Natural Product Reports. 2012;29(9):1007-21.

4. Davies J. Where have all the antibiotics gone?. Canadian Journal of Infectious Diseases and Medical Microbiology. 2006;17(5):287-90.

5. WHO. The Evolving Threat of Antimicrobial Resistance: Options for Action World Health Organization. 2014. http://apps.who.int/iris/bitstream/10665/ 44812/1/9789241503181_eng.pdf.

6. Cheesman MJ, Ilanko A, Blonk B, Cock IE. Developing new antimicrobial therapies: Are synergistic combinations of plant extracts/compounds with conventional antibiotics the solution?. Pharmacognosy Reviews. 2017;11(22):57-72.

7. Vuuren SV, Viljoen A. Plant-based antimicrobial studies-methods and approaches to study the interaction between natural products. Planta Medica. 2011;77(11):1168-82

8. Cottarel G, Wierzbowski J. Combination drugs, an emerging option for antibacterial therapy. Trends in Biotechnology. 2007;25(12):547-55.

9. Hemaiswarya S, Kruthiventi AK, Doble M. Synergism between natural products and antibiotics against infectious diseases. Phytomedicine. 2008:15(8):639-52.

10. Cock IE. Medicinal and aromatic plants - Australia. in Ethnopharmacology section, Biological, Physiological and Health Sciences. Encyclopedia of Life Support Systems. 2011. Developed under the Auspices of the UNESCO, EOLSS Publishers, Oxford, UK, (http://www.eolss.net).

11. Kalt FR, Cock IE. GC-MS analysis of bioactive Petalostigma extracts: Toxicity, antibacterial and antiviral activities. Pharmacognosy Magazine. 2014;10(37 Suppl):S37-48
12. Courtney R, Sirdaarta J, Matthews B, Cock IE. Tannin components and inhibitory activity of Kakadu plum leaf extracts against microbial triggers of autoimmune inflammatory diseases. Pharmacognosy Journal. 2015:7(1):18-31. DOI: 10.5530/ pj.2015.7.2

13. Vesoul J, Cock IE. The potential of bunya nut as an antibacterial food agent. Pharmacognosy Communications. 2012;2(1):72-9. DOI: 10.5530/pc.2012.1.13

14. Eloff JN. A Sensitive and quick microplate method to determine the minimal inhibitory concentration of plant extracts for bacteria. Planta Medica. 1998;64(08):711-3.

15. Hübsch Z, Van Z RL, Cock IE, Vuuren SFV. Interactive antimicrobial and toxicity profiles of conventional antimicrobials with Southern African medicinal plants. South African Journal of Botany. 2014;93:185-97.

16. Ruebhart D, Wickramasinghe W, Cock IE. Protective efficacy of the antioxidants vitamin $\mathrm{E}$ and Trolox against Microcystis aeruginosa and microcystin-LR in Artemia franciscana nauplii. Journal of Toxicology and Environmental Health, Part A. 2009;72(24):1567-75. DOI: 10.1080/15287390903232459

17. Kwast $\mathrm{KE}$. Oxygen and $\mathrm{pH}$ regulation of protein synthesis in mitochondria from Artemia franciscana embryos. Biochemical Journal. 1996;313(1):207-13.

18. Wright $\mathrm{MH}$, Lee CJ, Pollock CE, Greene AC, Cock IE. Growth inhibitory activity of selected high antioxidant Australian Syzygium species against the food poisoning and tissue necrotic pathogen Clostridium perfringens. Pharmacognosy Communications. 2016;6(2):93-9. DOI: 10.5530/pc.2016.2.7

19. Narayana KR, Reddy MS, Chaluvadi MR, Krishna DR. Bioflavonoids classification pharmacological, biochemical effects and therapeutic potential. Indian Journal of Pharmacology. 2001;33(1):2-16

20. Kaur GJ, Arora DS. Antibacterial and phytochemical screening of Anethum graveolens, Foeniculum vulgare and Trachyspermum ammi. BMC Complementary and Alternative Medicine. 2009;9(1):1.

21. Buzzini P, Arapitsas P, Goretti M, Branda E, Turchetti B, Pinelli P, et al. Antimicrobial activity of hydrolysable tannins. Medicinal Chemistry. 2008;8(12):1179-87.

22. Cowan MM. Plant products as antimicrobial agents. Clinical Microbiology Reviews. 1999:12(4):564-82

23. Chung PY, Navaratnam P, Chung LY. Synergistic antimicrobial activity between pentacyclic triterpenoids and antibiotics against Staphylococcus aureus strains. Annals of Clinical Microbiology and Antimicrobials. 2011;10(1):25

24. Ramón-Garcia S, Del RRG, Villarejo AS, Sweet GD, Cunningham F, Barros D, et al. Repurposing clinically approved cephalosporins for tuberculous therapy. Scientific Reports. 2016;6:34239.

25. Sahli AA, Abdulkhair WM. Inhibition of beta-lacamase enzyme of Pseudomonas aeruginosa by clavulanic acid of Rumex vesicarius L. African Journal of Agricultutal Research. 2011;6(12):2908-15.

26. Morel C, Stermitz FR, Tegos G, Lewis K. Isoflavones as potentiators of antibacterial activity. Journal of Agriculture and Food Chemistry. 2003;51(19):5677-9.

27. Dickson RA, Houghton PJ, Hylands PJ, Gibbons S. Antimicrobial, resistancemodifying effects, antioxidant and free radical scavenging activities of Mezoneuron benthamianum Baill, Securinega virosa Roxb and wild. and Microglossa pyrifolia Lam. Phytotherapy Research. 2006;20(1):41-5.

28. Stavrim M, Piddock LJV, Gibbons S. Bacterial efflux pump inhibitors from natura sources. Journal of Antimicrobial Chemotherapy. 2007;59(6):1247-60.

29. Santiago C, Pang EL, Lim KH, Loh HS, Ting KN. Inhibition of penicillin-binding protein 2a (PBP2a) in methicillin resistant Staphylococcus aureus (MRSA) by combination of ampicillin and a bioactive fraction from Duabanga grandiflora. BMC Complementary and Alternative Medicine. 2015;15(1):1.

30. Yap PSX, Yiap BC, Ping HC, Lim SHE. Essential oils, a new horizon in combating bacterial antibiotic resistance. The Open Microbiology Journal. 2014;8:6.

31. Mikulášová $M$, Chovanová $R$, Vaverková Š. Synergism between antibiotics and plant extracts or essential oils with efflux pump inhibitory activity in coping with multidrug-resistant Staphylococci. Phytochemistry Reviews. 2016;15(4):651-62

32. Brzoska AJ, Hassan KA, de Leon EJ, Paulsen IT, Lewis PJ. Single-step selection of drug resistant Acinetobacter baylyi ADP1 mutants reveals a functional redundancy in the recruitment of multidrug efflux systems. PloS One. 2013;8(2):e56090

33. Oteo J, Campos J, Lázaro E, Cuevas O, Garcia-Cobos S, Pérez-Vázquez M et al. Increased amoxicillin-clavulanic acid resistance in Escherichia coli blood isolates, Spain. Emerging Infectious Diseases. 2008;14(8):1259-62.

34. Toroglu S. In-vitro antimicrobial activity and synergistic/antagonistic effect of interactions between antibiotics and some spice essential oils. Journal of Environmental Biology. 2011;32(1):23-9. 
GRAPHICAL ABSTRACT

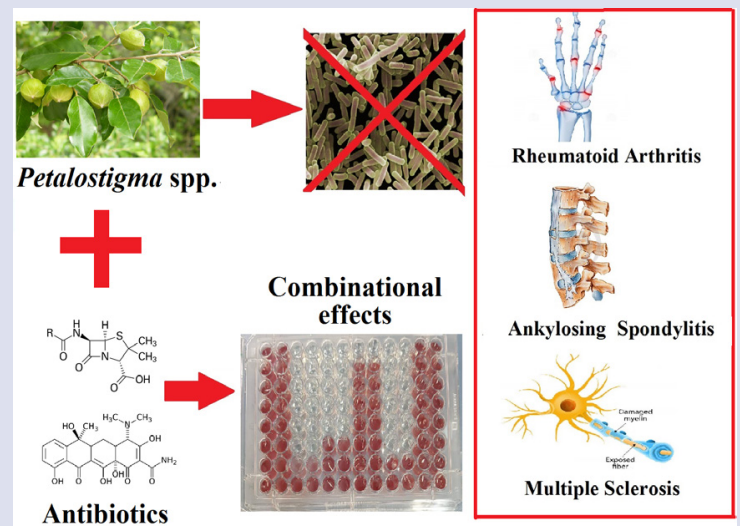

SUMMARY

- Petalostigma spp. methanolic and water extracts were screened for growth inhibitory activity against several microbes.

- Liquid dilution and disc diffusion techniques were used to quantify the efficacy of the extracts and compare them to conventional antibiotics.

- The extracts were also tested in combination with conventional antibiotics to determine whether the extracts cold potentiate the antibiotic activity.

- All synergistic combinations were tested in varying ratios of the antimicrobial components to determine the ideal ratios for therapeutic usage.

- Toxicity was evaluated using the Artemia nauplii bioassay.

\section{ABOUT AUTHORS}

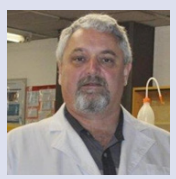

Dr. Ian Cock leads a research team in the Environmental Futures Research Institute and the School of Natural Sciences at Griffith University, Australia. His research involves bioactivity and phytochemical studies into a variety of plant species of both Australian and international origin including Aloe vera, South Asian and South American tropical fruits, as well as Australia plants including Scaevola spinescens, Pittosporum phylliraeoides, Terminalia ferdinandiana (Kakadu plum), Australian Acacias, Syzygiums, Petalostigmas and Xanthorrhoea johnsonii (grass trees). This range of projects has resulted in nearly 200 scientific publications in a variety of peer reviewed journals.

Cite this article: Ilanko A, Cock IE. The Interactive Antimicrobial Activity of Conventional Antibiotics and Petalostigma spp. Extracts Against Bacterial Triggers of some Autoimmune Inflammatory Diseases. Pharmacog J. 2019;11(2):292-309. 